\title{
Therapeutic Strategies in the Development of Anti-viral Drugs and Vaccines Against SARS-CoV-2 Infection
}

\author{
Jasvinder Singh Bhatti ${ }^{1}$ • Gurjit Kaur Bhatti ${ }^{2}$ • Naina Khullar ${ }^{3}$ • Arubala P. Reddy ${ }^{4}$ • P. Hemachandra Reddy ${ }^{5,6,7,8,9}$ (D)
}

Received: 28 June 2020 / Accepted: 11 August 2020 / Published online: 18 August 2020

(C) Springer Science+Business Media, LLC, part of Springer Nature 2020

\begin{abstract}
The whole world is currently facing a pandemic of an infectious disease known as novel coronavirus disease-2019 (COVID-19) caused by severe acute respiratory syndrome coronavirus-2 (SARS-CoV-2) . This outbreak emerged unexpectedly and imposed a potential threat to humans, associated with the social and economic burden on the individual and federal governments. COVID-19, which initially started in Wuhan City of China and then spread to the whole world, has been declared a Public Health Emergency of International Concern. The continuous increase in the number of confirmed cases leads to high mortality across the world. Growing evidence indicates that the mortality rate is very predominant in elderly people and those with preexisting health conditions. However, the potential pathogenesis of SARS-CoV-2 infection in humans is still unknown. The dysregulated/exuberant immune response may have substantially contributed to the SARS-CoV-2-mediated pathology. Nevertheless, there is no clinically approved drug/vaccine currently available that can restrict its pathogenesis. However, several drugs are currently shown to provide some therapeutic benefits for COVID-19 patients, including antiviral drugs that might have a significant role in restricting the current pandemic of COVID-19. In this article, we highlighted the pharmacological treatment strategies for COVID-19 and purposed the therapeutic targets for the development of vaccines or anti-viral drug molecules against SARS-CoV-2 infection in humans.
\end{abstract}

Keywords Novel coronavirus disease $\cdot$ COVID-19 $\cdot$ SARS-CoV-2 $\cdot$ Anti-viral drugs $\cdot$ Vaccine $\cdot$ Clinical trials

\section{Introduction}

In the past 2 decades, three coronavirus $(\mathrm{CoV})$ outbreaks occurred in the world [1]: severe acute respiratory syndrome

Jasvinder Singh Bhatti and Gurjit Kaur Bhatti contributed equally to this work.

P. Hemachandra Reddy

hemachandra.reddy@ttuhsc.edu

Jasvinder Singh Bhatti

jasvinder.bhatti@cup.edu.in

Gurjit Kaur Bhatti

bhattigk@yahoo.com

Naina Khullar

naina306@gmail.com

Arubala P. Reddy

arubala.reddy@ttuhsc.edu

1 Department of Human Genetics and Molecular Medicine, School of Health Sciences, Central University of Punjab, Bathinda, India

2 Department of Medical Lab Technology, University Institute of Applied Health Sciences, Chandigarh University, Mohali, Punjab, India coronavirus (SARS-CoV) in 2002 [2, 3], Middle East respiratory syndrome coronavirus (MERS-CoV) in 2012 [4], and SARS CoV-2 in 2019 [5]. The SARS-CoV epidemic emerged from an animal market in the Guangdong province of China

3 Department of Zoology, Mata Gujri College, Fatehgarh Sahib, Punjab, India

4 Arubala P Reddy, Nutritional Sciences Department, Texas Tech University, Lubbock, TX, USA

5 Department of Internal Medicine, Texas Tech University Health Sciences Center, Lubbock, TX, USA

6 Neuroscience \& Pharmacology, Texas Tech University Health Sciences Center, Lubbock, TX, USA

7 Neurology Department, School of Medicine, Texas Tech University Health Sciences Center, Lubbock, TX, USA

8 Public Health Department, Graduate School of Biomedical Sciences, Texas Tech University Health Sciences Center, Lubbock, TX, USA

9 Department of Speech, Language and Hearing Sciences, School of Health Professions, Texas Tech University Health Sciences Center, 3601 4th Street, Lubbock, TX 79430, USA 
and spread to 32 countries through air travel routes, infecting 8422 individuals and $916(10.87 \%)$ casualties from November 2002 to August 2003 [6, 7]. MERS-CoV was first reported to cause human infection in Saudi Arabia in 2012, where it remains a major public health concern, and spread over 27 countries, infecting a total of 2,494 individuals and claiming 868 $(34.77 \%)$ fatalities during the period April 2012 to December $2019[4,7,8]$.

The recent outbreak of coronavirus disease 2019 (COVID19) started in December 2019 in Wuhan City of China and spread through human-to-human transmission across the world [9-11]. It continues to cause severe infections in humans, posing significant threats to global public health. China initially reported to the World Health Organization (WHO) on December 31, 2019. Further, on March 11, 2020, the WHO declared COVID-19 a pandemic and imposed Public Health Emergency of International Concern [12]. The fatality rate of coronavirus MERS-CoV was (34.77\%) higher than that of SARS-CoV (10.87\%); however, SARS-CoV-2 transmitted rapidly in comparison to SARS-CoV and MERS-CoV [13] and accounts for 3.4\% deaths all over the world [14]. The mortality rate of COVID-19 varies from one country to another. However, these fatality rates also vary with the age range of the infected persons. COVID-19 primarily spread through respiratory droplets. The manifestation of SARS-CoV-2 infections ranges from fever, cough, shortness of breath, fatigue, and, in a small population of patients, gastrointestinal infection symptoms to acute respiratory distress and pneumonia [15-17]. The loss of taste (ageusia) and loss of smell (anosmia) as one of the major symptoms of COVID-19 was initially ignored. However, further studies demonstrated a significant presence of ageusia and anosmia in the patients with COVID-19 infection [18-20]. The reproductive number of SARS-CoV-2 infection is estimated to be 2-3 [11], and the elderly people with underlying complications such as diabetes, heart disease, lung disease, cancer, etc. are more susceptible to severe infection and fatality [21-24]. Currently, there is no clinically approved drug/vaccine for the treatment of this disease. All the health organizations across the globe are on high alert and treating COVID-19 patients with the available drugs used in other respiratory infections. However, several potent candidates of antivirals and repurposed drugs are under urgent investigation [9]. This article highlighted the recent updates on the epidemiology, antiviral drugs used, and possible therapeutic strategies for the development of a vaccine against SARS-CoV-2 pathology.

\section{Epidemics of COVID-19}

According to recent WHO updates, globally, there are about 18 million confirmed cases and rising in American, European, and Southeast Asian countries [14]. To date, 216 countries and territories have been affected by the COVID-19 pandemic with a $5.9 \%$ mortality rate estimated by the WHO. Although the disease is now better contained in the suspected origin, the USA has witnessed the biggest surge in coronavirus cases over the past few months which accounts for around one quarter of the total number of infections worldwide. The USA, Brazil, and India are the most affected countries, contributing about half of the COVID-19-infected people across the world [14]. European countries witnessed the maximum number of coronavirus-related deaths than any part of the world followed by the USA. However, the actual total death toll may be higher than the number of confirmed deaths, due to limited testing and problems in the attribution of the cause of death and the difference between reported confirmed deaths and total deaths that varies by country to country. Surprisingly, men are at a significantly higher risk of having severe symptoms and fatalities, compared to women [14]. A maximum number of infected individuals are in the age group of 2145 years; however, the fatalities are more in elderly patients, i.e., above 60 years. If the current situation prevails for a longer duration and no therapeutic drug/vaccine is available, it is expected that almost one third of the world population may get infected and millions of deaths occur, worldwide.

\section{Etiology of COVID-19}

The coronaviruses belong to a large subfamily, Orthocoronavirinae, of the Coronaviridae family within the Nidovirales order and are classified into 4 genera: Alpha $(\alpha)$, Beta $(\beta)$, Gamma $(\gamma)$, and Delta $(\delta)$ coronavirus. They are single-stranded RNA viruses (+ssRNA) genomes with the size ranging from 26 to 32 kilobases, with a crown-like appearance due to the presence of spike glycoproteins on the envelope. They are known to infect both humans and animals. SARS-CoVs, MERS-CoVs, and SARS-CoV-2 are classified as $\beta$-coronavirus family members [25]. There are structural similarities between the MERS-CoV and SARS-CoV; however, they target the host cells through different receptors, dipeptidyl peptidase 4 (DDP4) and angiotensin-converting enzyme 2 (ACE2) respectively [26, 27]. The coronavirus particle, virion, consists of a nucleocapsid, containing singlestranded genomic RNA and phosphorylated nucleocapsid (N) protein, which is covered inside the phospholipid bilayers having two different types of spike proteins (Fig. 1), the spike glycoprotein trimmer $(\mathrm{S})$ that is present in almost all the CoVs and the hemagglutinin-esterase (HE) that is found in few CoVs. The membrane (M) and envelope (E) proteins are located among the $\mathrm{S}$ proteins in the virus envelope [28]. SARSCoV-2 is a positive-sense, single-stranded RNA virus containing 29,891 nucleotides, encoding for 9860 amino acids [29]. Although its origin is not entirely understood, the genomic 


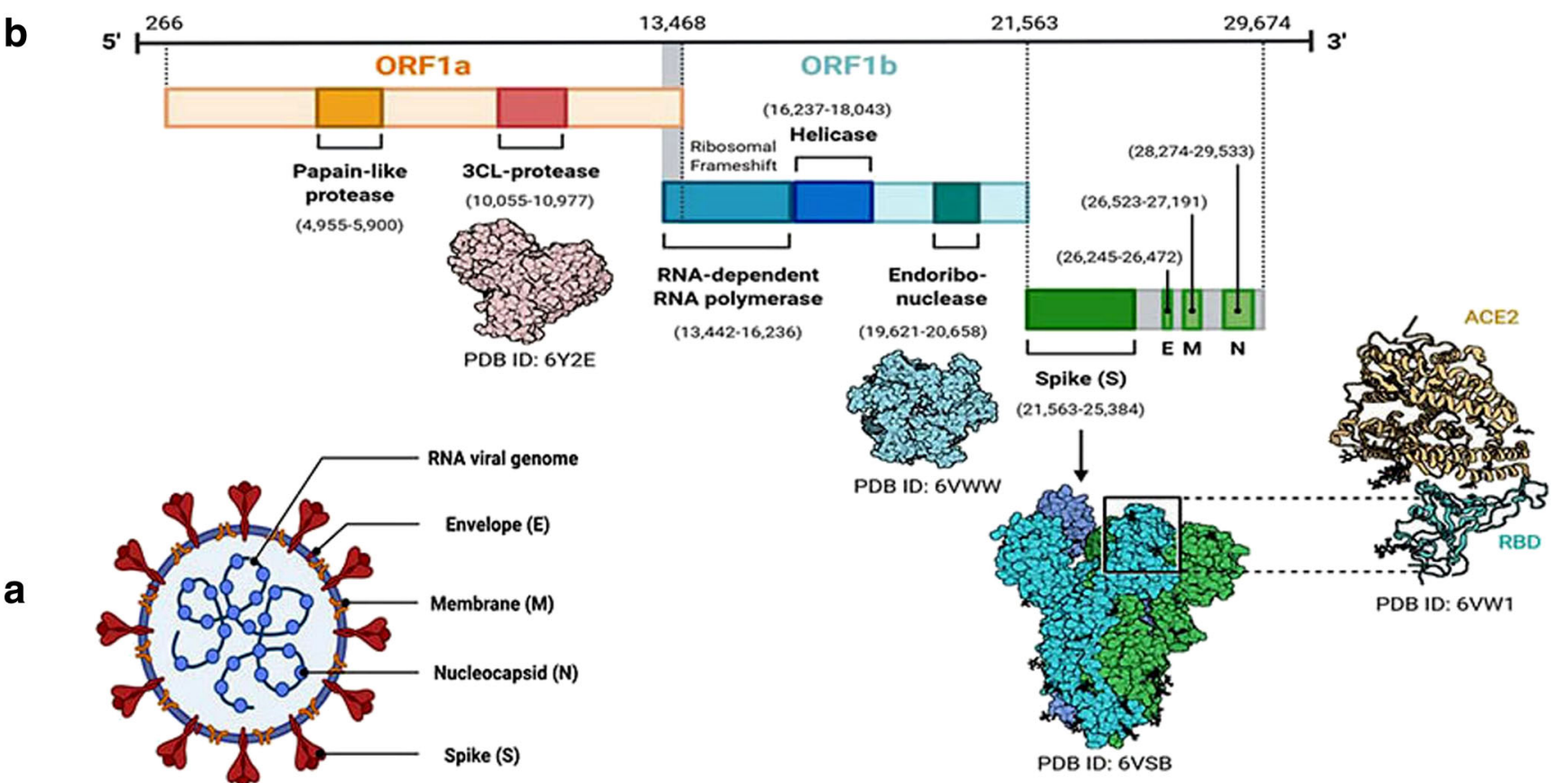

Fig. 1 (A) Structure of SARS-CoV-2 particle, virion, and (B) genomic organization of SARS-CoV-2 (adapted from Chan et al. 2020). A SARS$\mathrm{CoV}-2$ particle is approximately $70-90 \mathrm{~nm}$ in size, $30 \mathrm{~kb}$, an ssRNA virus, similar in structure to the SARS-CoV virion, and belongs to the family Coronaviridae. It has a crown shape with spikes on the membrane

analyses suggest that SARS-CoV-2 probably evolved from a strain found in bats [30].

Recently, bioinformatic analysis of a virus genome from a patient with COVID-19 shows that the genome of SARSCoV-2 shows $89 \%$ nucleotide identity with batSARS-likeCoVZXC21 and 82\% with that of human SARS-CoV [29]. The phylogenetic trees of their orfla/b, spike, envelope, membrane, and nucleoprotein also clustered closely with those of the bat, civet, and human SARS coronaviruses. Further, additional genomic studies suggest that SARSCoV-2 shared $79 \%$ nucleotide identity to SARS-CoV and $51.8 \%$ identity to MERS-CoV [31,32]. Figure 2 shows the comparative analysis of the genomic organization of various coronaviruses in different species. All these studies indicated a high genetic homology among SARS-CoV-2, MERS-CoV, and SARS-CoV. SARS-CoV-2 uses the same receptor, angiotensin-converting enzyme 2 (ACE2), as that for SARS-CoV to enter the target cell, and mainly spreads through the respiratory tract. ACE2 enzyme is involved in the regulation of blood pressure and is expressed by cells of the heart, lungs, kidneys, and intestines. SARS-CoV-2 binds to ACE2 through spike proteins. However, the external subdomain of the spike's receptor-binding domain of SARS-CoV-2 shares only $40 \%$ amino acid identity with other SARS-related coronaviruses [29]. So, the drugs targeting SARS-CoV and MERS-CoV might not be fit for the prevention of COVID-19. that are used to embed in the host membrane-derived lipid bilayer. (B) There are 6-11 open reading frames (ORFs) with $5^{\prime}$ and $3^{\prime}$ flanking untranslated regions (UTRs). The nsps constitutes dependent RNA polymerase (nsp12), main protease (nsp5), helicase (nsp13), and papain-like protease (nsp3)

\section{Current Scenario of Possible Therapeutic Drugs Against SARS-CoV-2 Infection}

To date, we do not have any clinically approved antiviral drug or vaccine that can cure this disease. However, the battle to find a specific therapy for the recent pandemic of COVID-19 is still going on. Currently, various preventive measures including social distancing, hand sanitization, avoiding nonessential international/national travels, use of facial masks, etc. are used to restrict the further transmission of SARSCoV-2 infection across the world. Several pharmacological treatment possibilities are being explored to treat this infection. In the current situation of COVID-19 pandemic, possible repositioning of various antiviral and antiparasitic drugs including hydroxychloroquine and chloroquine, remdesivir, protease inhibitors - lopinavir and ritonavir, etc. previously used for SARS and MERS or other viral infections is now being followed to treat SARS-CoV-2 infection and might have gained significant improvement in pneumoniaassociated symptoms of some of the COVID-19 patients [9, 33-38].

Table 1 shows the clinical trials of repurposing various drugs as a possible therapeutic strategy against SARS-CoV2 infection. Remdesivir, a nucleotide analog, is a broadspectrum antiviral drug that inhibits RNA replication [30] and may be a promising anti-viral drug therapy for COVID19. Several studies demonstrated the effectiveness of 


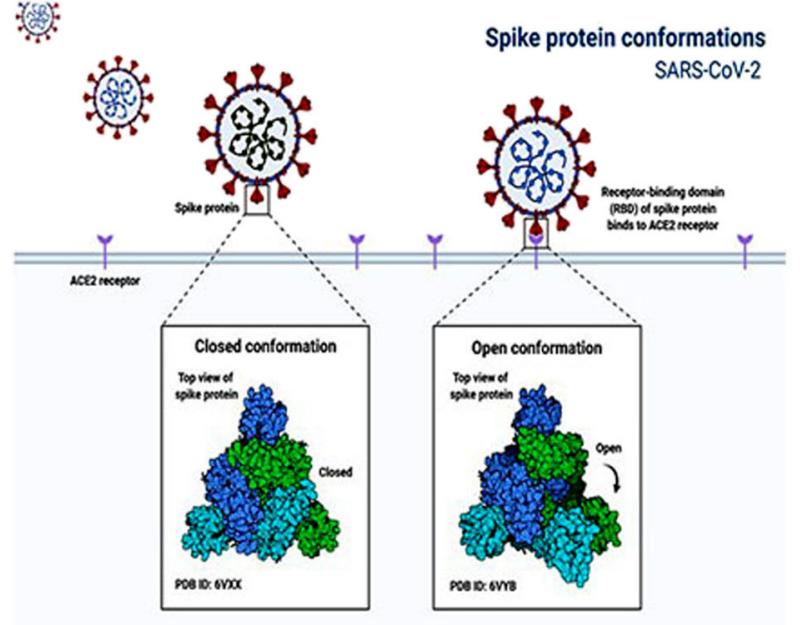

a

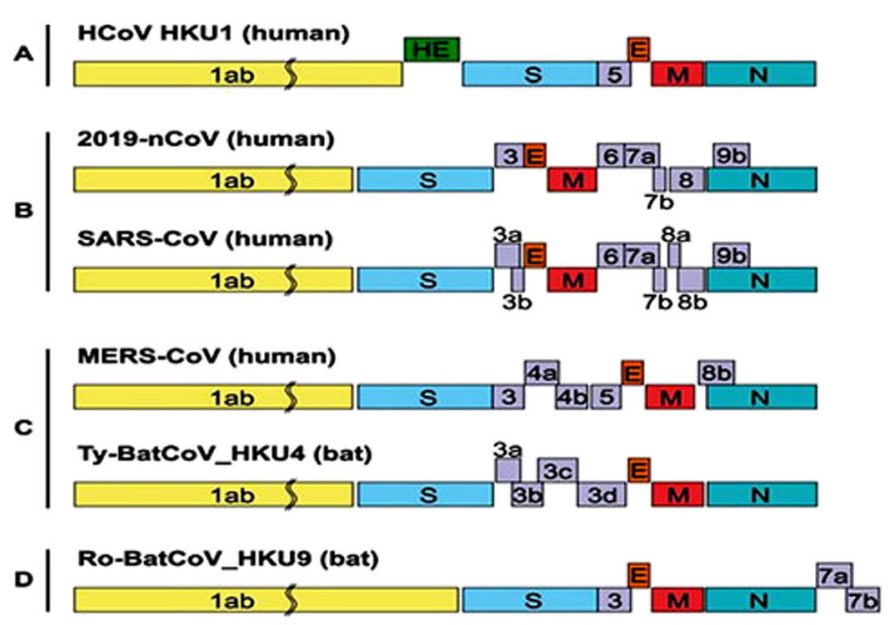

b

Fig. 2 a Spike protein conformation of SARS-CoV-2 and $\mathbf{b}$ schematic comparison of the genome organization of SARS-CoV and MERS-CoV

remdesivir in animal models of SARS-CoV-2-related coronaviruses [30, 39-41]. However, it was less effective against ebolavirus infections in humans [42]. Recently, clinical trials of remdesivir against COVID-19 are ongoing primarily in the USA and China [43].

Hydroxychloroquine is FDA-approved to prevent and treat malaria, as well as to treat the autoimmune diseases rheumatoid arthritis and lupus [44-48]. Some preliminary reports have suggested that hydroxychloroquine, alone or in combination with the FDA-approved antibiotic azithromycin, may benefit people with COVID-19. Numerous clinical trials are planned or underway, including a recently launched study supported by NIH's National Heart, Lung and Blood Institute, evaluating the safety and effectiveness of hydroxychloroquine for treatment of adults hospitalized with COVID-19.

The preliminary studies indicate that chloroquine and hydroxychloroquine have the potential to improve disease outcomes and possibly slow COVID-19's progression [49]. Other in vitro and clinical studies demonstrated that the antiviral action of hydroxychloroquine might be effective in limiting SARS-CoV-2 infection [49, 50]. Further, a combination of hydroxychloroquine and azithromycin has also been used against the pathophysiology of COVID-19 [51] and is under clinical trial against SARS-CoV-2.

The chloroquine drug appears to interfere with terminal glycosylation of ACE2 and exerts direct antiviral effects by inhibiting $\mathrm{pH}$-dependent steps of the replication in several viruses including coronaviruses showing a strong impact on SARS-CoV infection [52-55]. Moreover, chloroquine and hydroxychloroquine are known to modulate the immune response in some infectious diseases via inhibition of autophagy, controlling Toll-like receptor (TLR) signaling, and diminishing the cytokine storm by suppressing the production of TNF- $\alpha$ and IL- $6[52,56]$ and worked at both entry and post-entry stages of the COVID19 infection [35]. Currently, we are looking for therapeutic strategies to counter the severe effects of the SARS-CoV-2 infection. A preliminary clinical trial of chloroquine repurposing against SARS-CoV-2 infection has shown some positive results, which led to the start of several clinical trial studies across the world [35, 37]. Recently, the National Institutes of Health (NIH), USA, stopped the clinical trial of hydroxychloroquine as a potential therapy for COVID-19 because some studies show controversial results of this drug against SARS-CoV-2 [57]. Through the fog of alleged misconduct, hope, hype, and politicization that surrounds hydroxychloroquine, the malaria drug touted as a COVID-19 treatment, a scientific picture is now emerging. Recent systematic studies demonstrated no significant benefit of hydroxychloroquine drug in COVID-19 treatment [57, 58].

Besides, the clinical trials of a combination of two anti-HIV drugs - lopinavir and ritonavir-have also been started for these drugs against the SARS-CoV-2 pathology [59]. These drugs are used in a fixed-dose combination for the treatment and prevention of HIV/AIDS [60]. A recent study reported that the $\beta$-coronavirus viral loads of a COVID-19 patient in Korea were significantly reduced after lopinavir/ritonavir treatment [61]. In contrast, another clinical trial on hospitalized adult patients with severe COVID-19 shows no benefit with the lopinavir-ritonavir treatment [62].

In the past, vaccines were developed against SARS-CoV and MERS-CoV, but none of them has been clinically approved for use in humans [63]. Currently, several vaccination strategies have been undergoing against SARS-CoV using vaccine candidates including inactivated virus, a liveattenuated virus, viral vectors, subunit vaccines, recombinant proteins, DNA vaccines, etc. across the world. Additionally, many other options are being explored for the treatment of 
Table 1 Current status of clinical trial studies on the interventions against COVID-19 across the world as of July 31, 2020 (Source: National Institute of Health, https://clinicaltrials.gov/) Accessed on Aug 1, 2020

\begin{tabular}{ll}
\hline No. & Title \\
\hline $1 \quad$ Maternal-Foetal Transmission of \\
& SARS-Cov-2 \\
& \\
& \\
2 & COVID-19 Breastfeeding \\
& Guideline for \\
& African-Americans \\
& Comparison of the Efficacy of \\
& Rapid Tests to Identify \\
& COVID-19 Infection (CATCh \\
& COVID-19) \\
4 & The Role of a Private Hospital in \\
& Hong Kong Amid COVID-19 \\
& Pandemic \\
5 & Lung CT Scan Analysis of \\
& SARS-CoV2 Induced Lung \\
& Injury
\end{tabular}

6 Study Evaluating the Safety and Efficacy of Autologous Non-hematopoietic Peripheral Blood Stem Cells in Covid-19

7 Performance Evaluation of RealDetect ${ }^{\mathrm{TM}}$ COVID-19 RT-PCR Kit for the Detection of SARS-CoV-2 Virus Patient-Reported and Clinically Verified Olfactory Disorders (COVID-19)

9 Smell and Taste Disorders in COVID-19 Patients

10 Neonatal Complications of Coronavirus Disease (COVID-19)

11

$\begin{array}{ll}\text { Status } & \text { Conditions } \\ \text { Recruiting } & \begin{array}{c}\text { Maternal fetal infection } \\ \text { transmission } \\ \text { COVID-19 }\end{array} \\ & \text { SARS-CoV } 2 \\ & \\ \text { Not yet } & \text { COVID-19 } \\ \text { recruiti- } & \text { Exclusive breastfeeding } \\ \text { ng } & \\ \text { Not yet } & \text { COVID-19 } \\ \text { recruiti- } & \\ \text { ng } & \\ \text { Active, not } & \text { COVID } \\ \text { recruiti- } & \\ \text { ng } & \\ \text { Recruiting } & \text { COVID-19 }\end{array}$

Completed Coronavirus disease 2019 (COVID-19)

Recruiting High sensitivity and specificity (with $95 \%$ confidence interval) of RealDetect ${ }^{\mathrm{TM}}$ COVID-19 RT-PCR Kit

Completed COVID-19

Recruiting COVID-19

Recruiting Neonatal COVID-19 disease
Interventions Locations

Diagnostic test: diagnosis of SARS-Cov2 by RT-PCR and $\mathrm{IgG}, \mathrm{Ig} \mathrm{M}$ serologies in the amniotic fluid, the blood cord, and the placenta

Behavioral: COVID-19

breastfeeding support

- Meharry Medical College, Nashville, TN, USA

Diagnostic test: diagnostic tests for COVID-19 infection

Diagnostic test: COVID 19 diagnostic test

- Hong Kong Sanatorium \& Hospital, Hong Kong, Hong Kong

Other: lung CT scan analysis in • Ospedale Papa Giovanni XXIII, COVID-19 patients Bergamo, Italy

- Policlinico San Marco-San Donato group, Bergamo, Italy

- Azienda Ospedaliero-Universitaria di Ferrara, Ferrara, Italy

- ASST di Lecco Ospedale Alessandro Manzoni, Lecco, Italy

- ASST Melegnano-Martesana, Ospedale Santa Maria delle Stelle, Melzo, Italy

- ASST Monza, Monza, Italy

- AUSL Romagna-Ospedale Infermi di Rimini, Rimini, Italy

- Istituto per la Sicurezza Sociale-Ospedale della Repubblica di San Marino, San Marino, San Marino
Biological: autologous non-hematopoietic peripheral blood stem cells (NHPBSC)

Drug: COVID-19 standard care

Device: performance evaluation study of RealDetect RT-PCR Kit for COVID-19 detection
- Abu Dhabi Stem Cells Center, Abu Dhabi, United Arab Emirates

- Institute of Epidemiology, Disease Control and Research (IEDCR), Mohakhali, Dhaka (for sample collection and sample storage), Institute for Developing Science \& Health Initiatives (ideSHi); Mohakhali, Dhaka (for sample analysis, data collection, data analysis), Dhaka, Bangladesh

- Uhmontpellier, Montpellier, France anosmia, ageusia, and other

Other: investigation of smell and taste disorders

- ASST Monza-Ospedale San Gerardo, Monza, Italy

Other: no interventionexposure is to COVID-19 clinical symptoms
- Imperial College, London, UK

- CHU Amiens, Amiens, France 
Table 1 (continued)

\begin{tabular}{|c|c|c|c|c|c|}
\hline No. & Title & Status & Conditions & Interventions & Locations \\
\hline & $\begin{array}{l}\text { COVID-19 Infection in Patients } \\
\text { with Hepatocellular Carcinoma }\end{array}$ & & $\begin{array}{l}\text { Hepatocellular } \\
\text { carcinoma } \\
\text { COVID-19 }\end{array}$ & $\begin{array}{l}\text { Diagnostic test: nasopharyngeal } \\
\text { COVID-19 RT-PCR }\end{array}$ & \\
\hline 12 & $\begin{array}{l}\text { COVID-19 Prevalence and } \\
\text { Cognitive Deficits in } \\
\text { Neurological Patients }\end{array}$ & $\begin{array}{l}\text { Not yet } \\
\text { recruiti- } \\
\text { ng }\end{array}$ & $\begin{array}{l}\text { Neurological diseases or } \\
\quad \text { conditions } \\
\text { Stroke, acute } \\
\text { Seizure disorder }\end{array}$ & $\begin{array}{l}\text { Diagnostic test: COVID-19 } \\
\text { swap test PCR }\end{array}$ & $\begin{array}{l}\text { - Aalborg University Hospital, } \\
\text { Aalborg, DK, Denmark } \\
\text { - Aarhus University Hospital, } \\
\text { Aarhus, DK, Denmark } \\
\text { • Regional Hospital West Jutland, } \\
\text { Hostebro, Holstebro, DK, } \\
\text { Denmark } \\
\text { - Regional Hospital Central } \\
\text { Jutland, Viborg, Viborg, DK, } \\
\text { Denmark }\end{array}$ \\
\hline 13 & $\begin{array}{l}\text { Frailty in Elderly Patients with } \\
\text { COVID-19 }\end{array}$ & Recruiting & COVID-19 & $\begin{array}{l}\text { Other: relation between frailty } \\
\text { and clinical outcomes in } \\
\text { elderly patients with } \\
\text { COVID-19 }\end{array}$ & $\begin{array}{l}\text { - ASST Monza-Ospedale San } \\
\text { Gerardo, Monza, Italy }\end{array}$ \\
\hline 14 & $\begin{array}{l}\text { COVID-19 Convalescent Plasma } \\
\text { (CCP) Transfusion }\end{array}$ & Recruiting & COVID-19 & $\begin{array}{l}\text { Biological: COVID } \\
\text { convalescent plasma }\end{array}$ & $\begin{array}{c}\text { - University of Mississippi Medical } \\
\text { Center, Jackson, MS, USA }\end{array}$ \\
\hline 15 & $\begin{array}{l}\text { COVID-19 in the Swedish } \\
\text { ICU-Cohort: Risk Factors of } \\
\text { Critical Care Admission and } \\
\text { Intensive Care Mortality }\end{array}$ & $\begin{array}{l}\text { Not yet } \\
\quad \text { recruiti- } \\
\text { ng }\end{array}$ & $\begin{array}{l}\text { COVID-19 } \\
\text { Critical illness }\end{array}$ & $\begin{array}{l}\text { Other: COVID-19 and inten- } \\
\text { sive care }\end{array}$ & \\
\hline 16 & $\begin{array}{l}\text { MURDOCK Cabarrus County } \\
\text { COVID-19 Prevalence and } \\
\text { Immunity (C3PI) Study }\end{array}$ & $\begin{array}{l}\text { Enrolling } \\
\text { by } \\
\text { invita- } \\
\text { tion }\end{array}$ & COVID-19 & $\begin{array}{l}\text { Other: COVID-19 PCR and } \\
\text { serology testing }\end{array}$ & $\begin{array}{l}\text { - Duke CTSI Translational } \\
\text { Population Health Office, } \\
\text { Kannapolis, NC, USA }\end{array}$ \\
\hline 17 & $\begin{array}{l}\text { Rapid Diagnostic Test for } \\
\text { COVID-19 Based on Antibody } \\
\text { Detection (YCOVID) }\end{array}$ & $\begin{array}{l}\text { Active, not } \\
\text { recruiti- } \\
\text { ng }\end{array}$ & COVID-19 & $\begin{array}{l}\text { Diagnostic test: ELISA and } \\
\text { Rapid test to detect } \\
\text { antibodies against } \\
\text { COVID-19 }\end{array}$ & $\begin{array}{c}\text { - Parc Tauli University Hospital, } \\
\text { Sabadell, Barcelona, Spain }\end{array}$ \\
\hline 18 & $\begin{array}{l}\text { The Assessment of the Prevalence, } \\
\text { Clinical Course and Treatment } \\
\text { of COVID-19 Complications }\end{array}$ & $\begin{array}{l}\text { Enrolling } \\
\text { by } \\
\text { invita- } \\
\text { tion }\end{array}$ & $\begin{array}{l}\text { COVID-19 } \\
\text { Coronavirus infection } \\
\text { SARS-CoV-2 } \\
\text { Complications }\end{array}$ & $\begin{array}{l}\text { Other: complex diagnostic } \\
\text { panel }\end{array}$ & $\begin{array}{l}\text { - Silesian Centre for Heart Disease, } \\
\text { Zabrze, Silesia, Poland }\end{array}$ \\
\hline 19 & $\begin{array}{l}\text { COVID19-Convalescent Plasma } \\
\text { for Treating Patients with Active } \\
\text { Symptomatic COVID } 19 \\
\text { Infection (FALP-COVID) }\end{array}$ & Recruiting & $\begin{array}{l}\text { COVID-19 infection } \\
\text { Cancer patients } \\
\text { General population }\end{array}$ & $\begin{array}{l}\text { Biological: convalescent } \\
\text { plasma from COVID-19 do- } \\
\text { nors }\end{array}$ & $\begin{array}{c}\text { Fundacion Arturo Lopez Perez, } \\
\text { Providencia, Santiago, Chile }\end{array}$ \\
\hline 20 & COVID-19 Endoscopy Survey & Completed & COVID-19 & Other: practice details & $\begin{array}{l}\text { - Kings County Hospital Center, } \\
\text { Brooklyn, NY, USA; Albertson, } \\
\text { NY, USA } \\
\text { - Faculty of Medicine, Zagazig } \\
\text { University, Zagazig, Sharkia, } \\
\text { Egypt } \\
\text { - Al-Azhar Univerisity, Cairo, } \\
\text { Egypt } \\
\text { - Ahvaz Imam hospital, Ahvaz, } \\
\text { Iran, Islamic Republic of }\end{array}$ \\
\hline 21 & $\begin{array}{l}\text { Survey: COVID-19 Patients } \\
\text { Managed in the Operating } \\
\text { Theatre of Belgian Hospitals }\end{array}$ & Recruiting & COVID-19 & & $\begin{array}{l}\text { - Cliniques Universitaires Saint } \\
\text { Luc, Brussels, Belgium }\end{array}$ \\
\hline 22 & $\begin{array}{l}\text { COVID-19 Surveillance of Patients } \\
\text { and Healthcare Workers in a } \\
\text { Hospital Department }\end{array}$ & $\begin{array}{l}\text { Enrolling } \\
\text { by } \\
\text { invita- } \\
\text { tion }\end{array}$ & COVID-19 & $\begin{array}{l}\text { Diagnostic test: COVID-19 } \\
\text { test, polymerase chain reac- } \\
\text { tion for SARS-CoV-2 }\end{array}$ & $\begin{array}{l}\text { - Rigshospitalet University } \\
\text { Hospital of Copenhagen, } \\
\text { Copenhagen, Denmark }\end{array}$ \\
\hline 23 & $\begin{array}{l}\text { Viral Infection and Respiratory } \\
\text { Illness Universal Study } \\
\text { [VIRUS]: COVID-19 Registry }\end{array}$ & Recruiting & Coronavirus & Other: observational & $\begin{array}{l}\text { - Mayo Clinic in Arizona, } \\
\text { Scottsdale, AZ, USA } \\
\text { - Mayo Clinic in Florida, } \\
\text { Jacksonville, FL, USA }\end{array}$ \\
\hline
\end{tabular}


Table 1 (continued)

\begin{tabular}{|c|c|c|c|c|c|}
\hline No. & Title & Status & Conditions & Interventions & Locations \\
\hline & & & & & $\begin{array}{l}\text { - Society of Critical Care Medicine } \\
\text { (150+ sites), Chicago, IL, USA } \\
\text { - Rahul Kashyap, Rochester, MN, } \\
\text { USA }\end{array}$ \\
\hline 24 & $\begin{array}{l}\text { Predictive Factors COVID-19 } \\
\text { Patients }\end{array}$ & Recruiting & COVID-19 & $\begin{array}{l}\text { Other: predictive factors for } \\
\text { clinical response in patients } \\
\text { with COVID-19 }\end{array}$ & $\begin{array}{l}\text { - ASST Monza-Ospedale San } \\
\text { Gerardo, Monza, Italy }\end{array}$ \\
\hline 25 & $\begin{array}{l}\text { Characteristics and Outcome of } \\
\text { Coronavirus Disease } 2019 \\
\text { (COVID-19) in Egypt }\end{array}$ & $\begin{array}{l}\text { Not yet } \\
\text { recruiti- } \\
\text { ng }\end{array}$ & $\begin{array}{l}\text { Characteristic diseases } \\
\text { Outcome, fatal }\end{array}$ & Other: follow-up & \\
\hline 26 & $\begin{array}{l}\text { Detection of Anti-COVID-19 } \\
\text { Antibody Levels in an Hospital } \\
\text { Population }\end{array}$ & Recruiting & COVID-19 & $\begin{array}{l}\text { Diagnostic test: detection of } \\
\text { anti-COVID-19 antibody } \\
\text { level }\end{array}$ & $\begin{array}{c}\text { - Humanitas Rozzano/San Pio X, } \\
\text { Rozzano, Lombardia, Italy }\end{array}$ \\
\hline 27 & $\begin{array}{l}\text { Isotretinoin in Treatment of } \\
\text { COVID-19 }\end{array}$ & $\begin{array}{l}\text { Not yet } \\
\quad \text { recruiti- } \\
\text { ng }\end{array}$ & COVID-19 & $\begin{array}{l}\text { Drug: isotretinoin only product } \\
\text { in oral dose form }\end{array}$ & \\
\hline 28 & $\begin{array}{l}\text { Convalescent Plasma for Patients } \\
\text { with COVID-19: a Pilot Study }\end{array}$ & $\begin{array}{l}\text { Not yet } \\
\text { recruiti- } \\
\text { ng }\end{array}$ & $\begin{array}{l}\text { Coronavirus } \\
\text { Coronavirus infection }\end{array}$ & Drug: plasma & $\begin{array}{l}\text { - Universidad del Rosario, Bogota, } \\
\text { Cundinamarca, Colombia }\end{array}$ \\
\hline 29 & $\begin{array}{l}\text { Slovenian National COVID-19 } \\
\text { Prevalence Study }\end{array}$ & Recruiting & $\begin{array}{l}\text { COVID-19 } \\
\text { SARS-CoV-2 }\end{array}$ & $\begin{array}{l}\text { Diagnostic test: no intervention } \\
\text { planned due to the } \\
\text { observational study design- } \\
\text { only a diagnostic testing }\end{array}$ & $\begin{array}{l}\text { - University of Ljubljana, } \\
\text { Ljubljana, Slovenia }\end{array}$ \\
\hline 30 & $\begin{array}{l}\text { Incidence of COVID-19 Test } \\
\text { Conversion in Post-surgical } \\
\text { Patients }\end{array}$ & Recruiting & SARS-CoV-2 & $\begin{array}{l}\text { Diagnostic test: COVID-19 } \\
\text { PCR and serology }\end{array}$ & $\begin{array}{l}\text { - North Shore University Hospital, } \\
\text { Manhasset, NY, USA } \\
\text { - Long Island Jewish Medical } \\
\text { Center, New Hyde Park, NY, } \\
\text { USA }\end{array}$ \\
\hline 31 & $\begin{array}{l}\text { Novel COVID-19, a National } \\
\text { Analysis }\end{array}$ & Recruiting & COVID-19 & $\begin{array}{l}\text { Other: prevalence of } \\
\text { COVID-19 }\end{array}$ & $\begin{array}{l}\text { - Assiut University Hospitals, } \\
\text { Assiut, Egypt }\end{array}$ \\
\hline 32 & $\begin{array}{l}\text { Convalescent Plasma for Patients } \\
\text { with COVID-19: a Randomized, } \\
\text { Open Label, Parallel, Controlled } \\
\text { Clinical Study }\end{array}$ & $\begin{array}{l}\text { Not yet } \\
\text { recruiti- } \\
\text { ng }\end{array}$ & $\begin{array}{l}\text { Coronavirus } \\
\text { Coronavirus infection }\end{array}$ & $\begin{array}{l}\text { Drug: plasma } \\
\text { Drug: hydroxychloroquine }\end{array}$ & $\begin{array}{l}\text { - Universidad del Rosario, Bogota, } \\
\text { Cundinamarca, Colombia }\end{array}$ \\
\hline 33 & $\begin{array}{l}\text { Methodist Health System } \\
\text { COVID-19 Patient Registry }\end{array}$ & $\begin{array}{l}\text { Not yet } \\
\text { recruiti- } \\
\text { ng }\end{array}$ & COVID-19 & Other: treatment for COVID-19 & $\begin{array}{l}\text { - Clinical Research Institute } \\
\text { Methodist Health System, } \\
\text { Dallas, TX, USA }\end{array}$ \\
\hline 34 & $\begin{array}{l}\text { Safety and Efficacy of Melatonin in } \\
\text { Outpatients Infected with } \\
\text { COVID-19 }\end{array}$ & $\begin{array}{l}\text { Not yet } \\
\quad \text { recruiti- } \\
\text { ng }\end{array}$ & COVID-19 & $\begin{array}{l}\text { Drug: melatonin } \\
\text { Other: placebo } \\
\quad \text { (methylcellulose) capsule }\end{array}$ & $\begin{array}{l}\text { - University at Buffalo, Buffalo, } \\
\text { NY, USA }\end{array}$ \\
\hline 35 & $\begin{array}{l}\text { Discovery Stage } \\
\text { (Proof-of-Concept) COVID-19 } \\
\text { Antigen Presentation } \\
\text { Therapeutic Vaccine }\end{array}$ & $\begin{array}{l}\text { Active, not } \\
\text { recruiti- } \\
\text { ng }\end{array}$ & COVID-19 & $\begin{array}{l}\text { Biological: COVID-19 thera- } \\
\text { peutic vaccine } \\
\text { - Nucleocapsid-GM-CSF pro- } \\
\text { tein lactated Ringer's injec- } \\
\text { tion }\end{array}$ & $\begin{array}{l}\text { - Medicine Invention Design } \\
\text { Incorporation (MIDI) - } \\
\text { IORG0007849, North Bethesda, } \\
\text { MD, USA }\end{array}$ \\
\hline 36 & $\begin{array}{l}\text { Dynamic Evaluation of COVID-19 } \\
\text { Diagnostic Tests }\end{array}$ & $\begin{array}{l}\text { Not yet } \\
\text { recruiti- } \\
\text { ng }\end{array}$ & COVID-19 & $\begin{array}{l}\text { Diagnostic test: COVID-19 di- } \\
\text { agnostic test }\end{array}$ & \\
\hline 37 & $\begin{array}{l}\text { NGS Diagnostic in COVID-19 } \\
\text { Hosts - Genetic Cause Relating } \\
\text { to the Course of Disease } \\
\text { Progression }\end{array}$ & $\begin{array}{l}\text { Not yet } \\
\text { recruiti- } \\
\text { ng }\end{array}$ & COVID-19 & $\begin{array}{l}\text { Genetic: whole genome } \\
\text { analysis } \\
\text { Genetic: T cell receptor (TCR) } \\
\text { repertoire } \\
\text { Genetic: SARS-CoV-2 viral } \\
\text { composition }\end{array}$ & \\
\hline 38 & $\begin{array}{l}\text { Beaumont Health Large-Scale } \\
\text { Automated Serologic Testing for } \\
\text { COVID-19 }\end{array}$ & Recruiting & $\begin{array}{l}\text { COVID-19 } \\
\text { Coronavirus infection } \\
\text { Severe acute respiratory } \\
\quad \text { syndrome } \\
\quad \text { coronavirus } 2\end{array}$ & $\begin{array}{l}\text { Diagnostic test: } \\
\text { EUROIMMUN assay }\end{array}$ & $\begin{array}{l}\text { - Beaumont Health System, Royal } \\
\text { Oak, MI, USA } \\
\text { • Beaumont Health, Royal Oak, } \\
\text { MI, USA }\end{array}$ \\
\hline 39 & $\begin{array}{l}\text { Assessment of Obstetric, Fetal and } \\
\text { Neonatal Risks and Vertical }\end{array}$ & Recruiting & Pregnancy & $\begin{array}{c}\text { Diagnostic test: COVID } 19 \\
\text { diagnostic test by PCR }\end{array}$ & $\begin{array}{l}\text { - University Hospital of Toulouse, } \\
\text { Toulouse, France }\end{array}$ \\
\hline
\end{tabular}


Table 1 (continued)

\begin{tabular}{|c|c|c|c|c|c|}
\hline No. & Title & Status & Conditions & Interventions & Locations \\
\hline & $\begin{array}{l}\text { SARS-CoV-2 Transmission } \\
\text { During COVID-19 Pandemic }\end{array}$ & & & & \\
\hline 40 & $\begin{array}{l}\text { Minimal Invasive Autopsies to } \\
\text { Investigate Changes in Deceased } \\
\text { COVID-19 Patients }\end{array}$ & Recruiting & COVID-19 & $\begin{array}{l}\text { Procedure: CT-scan with mini- } \\
\text { mal invasive autopsy }\end{array}$ & - Jessa Hospital, Hasselt, Belgium \\
\hline 41 & $\begin{array}{l}\text { Exchange Transfusion Versus } \\
\text { Plasma from Convalescent } \\
\text { Patients with Methylene Blue in } \\
\text { Patients with COVID-19 }\end{array}$ & Recruiting & COVID-19 & $\begin{array}{l}\text { Biological: exchange blood } \\
\text { transfusion from normal } \\
\text { donor } \\
\text { Biological: plasma from } \\
\text { convalescent patients with } \\
\text { COVID-19 } \\
\text { Drug: Methylene Blue } 5 \\
\text { MG/ML }\end{array}$ & $\begin{array}{l}\text { - Ain Shams University, Cairo, } \\
\text { Egypt }\end{array}$ \\
\hline 42 & $\begin{array}{l}\text { Clinical Characteristics and } \\
\text { Outcomes of Pediatric } \\
\text { COVID-19 }\end{array}$ & Recruiting & $\begin{array}{l}\text { COVID-19 } \\
\text { SARS-CoV-2 infection } \\
\text { Pediatric ALL } \\
\text { Pneumonia, viral } \\
\text { Pandemic response }\end{array}$ & $\begin{array}{l}\text { Other: exposure (not } \\
\text { intervention)- } \\
\text { SARS-CoV-2 infection }\end{array}$ & $\begin{array}{l}\text { - University of Calgary/Alberta } \\
\text { Children's Hospital, Calgary, } \\
\text { Alberta, Canada }\end{array}$ \\
\hline 43 & $\begin{array}{l}\text { Relation Between Lab Finding and } \\
\text { COVID-19 Severity }\end{array}$ & $\begin{array}{l}\text { Not yet } \\
\text { recruiti- } \\
\text { ng }\end{array}$ & COVID-19 & $\begin{array}{l}\text { Diagnostic test: D-dimer, CBC. } \\
\text { ESR, CRP } \\
\text { Diagnostic test: liver function } \\
\text { tests, serum ferritin, and PCR } \\
\text { for COVID-19 }\end{array}$ & \\
\hline 44 & $\begin{array}{l}\text { Setting Up a COVID-19 Care } \\
\text { Facility at a Prison in Pakistan }\end{array}$ & Completed & COVID-19 & Other: COVID-19 facility & $\begin{array}{l}\text { - Camp Jail/COVID-19 care } \\
\text { facility/SIMS, Lahore, Pakistan }\end{array}$ \\
\hline 45 & $\begin{array}{l}\text { Impact of COVID-19 on } \\
\text { Marshallese Communities in the } \\
\text { U.S. }\end{array}$ & $\begin{array}{l}\text { Not yet } \\
\text { recruiti- } \\
\text { ng }\end{array}$ & COVID-19 & $\begin{array}{l}\text { Other: assessing impact of } \\
\text { COVID-19 }\end{array}$ & \\
\hline 46 & $\begin{array}{l}\text { Thorax Computed Tomography } \\
\text { Severity Score and Outcome in } \\
\text { COVID-19 Patients }\end{array}$ & Recruiting & COVID-19 & Diagnostic test: CT scan & $\begin{array}{l}\text { - Tepecik Training and Research } \\
\text { Hospital, Izmir, Izmir, Konak, } \\
\text { Turkey }\end{array}$ \\
\hline 47 & $\begin{array}{l}\text { Antibody Based Tests for } \\
\text { SARSCOV-2 } \\
\text { COVID-19-Evaluation of } \\
\text { Patients and Healthcare } \\
\text { Providers in the Confines of } \\
\text { Healthcare Settings }\end{array}$ & Recruiting & COVID-19 & $\begin{array}{l}\text { Diagnostic test: } \\
\text { CoronaCideTM COVID-19 } \\
\text { IgM/IgG Rapid Test and } \\
\text { Premier Biotech COVID-19 } \\
\text { IgM/IgG Rapid Test }\end{array}$ & $\begin{array}{l}\text { - St. David's Medical Center, } \\
\text { Austin, TX, USA }\end{array}$ \\
\hline 48 & $\begin{array}{l}\text { Spartan COVID-19 System: } \\
\text { Evaluation of Clinical Sample } \\
\text { Collection }\end{array}$ & Recruiting & COVID-19 & $\begin{array}{l}\text { Device: Spartan COVID-19 } \\
\text { System }\end{array}$ & $\begin{array}{l}\text { - Humber River Hospital, North } \\
\text { York, Ontario, Canada } \\
\text { - The University of Ottawa Heart } \\
\text { Institute, Ottawa, Ontario, } \\
\text { Canada }\end{array}$ \\
\hline 49 & $\begin{array}{l}\text { Classification of COVID-19 } \\
\text { Infection in Posteroanterior } \\
\text { Chest X-rays }\end{array}$ & Completed & COVID-19 & Device: $\operatorname{CovX}$ & - Dascena, Oakland, CA, USA \\
\hline 50 & $\begin{array}{l}\text { Rapid, Onsite COVID-19 } \\
\text { Detection }\end{array}$ & $\begin{array}{l}\text { Enrolling } \\
\text { by } \\
\text { invita- } \\
\text { tion }\end{array}$ & $\begin{array}{l}\text { COVID-19 } \\
\text { SARS-CoV-2 }\end{array}$ & $\begin{array}{l}\text { Device: Rapid Onsite } \\
\text { COVID-19 detection }\end{array}$ & $\begin{array}{l}\text { - University of Wisconsin, } \\
\text { Madison, WI, USA }\end{array}$ \\
\hline 51 & $\begin{array}{l}\text { Safety and Efficacy Of } \\
\text { Hydroxychloroquine for At Risk } \\
\text { Population (SHARP) Against } \\
\text { COVID-19 }\end{array}$ & $\begin{array}{l}\text { Not yet } \\
\text { recruiti- } \\
\text { ng }\end{array}$ & $\begin{array}{l}\text { Coronavirus infection } \\
\text { Hydroxychloroquine } \\
\text { adverse reaction }\end{array}$ & $\begin{array}{l}\text { Drug: hydroxychloroquine } \\
\text { sulfate } 200 \mathrm{mg}(\mathrm{mg}) \text { tab }\end{array}$ & \\
\hline 52 & Validation of COVID-19 Tests & $\begin{array}{l}\text { Active, not } \\
\text { recruiti- } \\
\text { ng }\end{array}$ & COVID-19 & $\begin{array}{l}\text { Diagnostic test: Covid-19 } \\
\text { Rapid Test Kit } \\
\text { (RAPG-COV-019) } \\
\text { Diagnostic test: quantitative } \\
\text { IgG test }\end{array}$ & $\begin{array}{l}\text { - Richmond Pharmacology Ltd. 1a } \\
\text { Newcomen St, London Bridge, } \\
\text { London, UK }\end{array}$ \\
\hline 53 & $\begin{array}{l}\text { Pulmonary Optical Coherence } \\
\text { Tomography in COVID-19 } \\
\text { Patients }\end{array}$ & Recruiting & $\begin{array}{l}\text { COVID-19 } \\
\text { Pulmonary embolism }\end{array}$ & $\begin{array}{l}\text { Diagnostic test: optical } \\
\text { coherence tomography } \\
(\mathrm{OCT})\end{array}$ & $\begin{array}{l}\text { - Incor - Heart Institute - University } \\
\text { of Sao Paulo, São Paulo, Brazil }\end{array}$ \\
\hline
\end{tabular}


Table 1 (continued)

\begin{tabular}{|c|c|c|c|c|c|}
\hline No. & Title & Status & Conditions & Interventions & Locations \\
\hline & & & & & $\begin{array}{l}\text { - IRCCS San Raffaele, Milano, } \\
\text { Italy }\end{array}$ \\
\hline 54 & $\begin{array}{l}\text { COVID-19 Surveillance Based on } \\
\text { Smart Wearable Device }\end{array}$ & $\begin{array}{l}\text { Not yet } \\
\text { recruiti- } \\
\text { ng }\end{array}$ & COVID-19 & & $\begin{array}{l}\text { - Peking University First Hospital, } \\
\text { Beijing, Beijing, China }\end{array}$ \\
\hline 55 & $\begin{array}{l}\text { Descriptive and Retrospective } \\
\text { Analysis of Acute Myocarditis } \\
\text { Associated with Pandemic } \\
\text { COVID-19 in Children }\end{array}$ & $\begin{array}{l}\text { Not yet } \\
\text { recruiti- } \\
\text { ng }\end{array}$ & COVID-19 & & $\begin{array}{l}\text { - Hôpital Bicêtre, Le } \\
\text { Kremlin-Bicêtre, France } \\
\text { - Hôpital Armand Trousseau, Paris, } \\
\text { France } \\
\text { - Hôpital Necker-Enfants Malades, } \\
\text { Paris, France } \\
\text { - Hôpital Robert Debré, Paris, } \\
\text { France }\end{array}$ \\
\hline 56 & $\begin{array}{l}\text { Diagnostic Value of New } \\
\text { COVID-19 Antibodies Testing } \\
\text { Among Laboratory Healthcare } \\
\text { Workers }\end{array}$ & $\begin{array}{l}\text { Not yet } \\
\quad \text { recruiti- } \\
\text { ng }\end{array}$ & COVID-19 & $\begin{array}{l}\text { Diagnostic test: COVID-19 an- } \\
\text { tibodies testing }\end{array}$ & \\
\hline 57 & $\begin{array}{l}\text { A Clinical Trial of Mycobacterium } \\
\text { w in Critically Ill COVID } 19 \\
\text { Patients }\end{array}$ & Recruiting & COVID-19 & $\begin{array}{l}\text { Drug: suspension of heat killed } \\
\text { (autoclaved) Mycobacterium } \\
\text { w } \\
\text { Drug: standard therapy of } \\
\text { COVID-19 }\end{array}$ & $\begin{array}{l}\text { - All India Institute of Medical } \\
\text { Science, Raipur, Raipur, } \\
\text { Chhattisgarh, India } \\
\text { - All India Institute of Medical } \\
\text { Sciences, Bhopal, Bhopal, } \\
\text { Madhya Pradesh, India } \\
\text { - Postgraduate Institute of Medical } \\
\text { Education and Research, } \\
\text { Chandigarh, India } \\
\text { - All India Institute of Medical } \\
\text { Science, Delhi, Delhi, India }\end{array}$ \\
\hline 58 & $\begin{array}{l}\text { Convalescent Plasma In ICU } \\
\text { Patients With } \\
\text { COVID-19-Induced Respiratory } \\
\text { Failure }\end{array}$ & Recruiting & $\begin{array}{l}\text { COVID-19 } \\
\text { SARS-CoV-2 }\end{array}$ & $\begin{array}{l}\text { Biological: multiple doses of } \\
\text { anti-SARS-CoV-2 convales- } \\
\text { cent plasma }\end{array}$ & $\begin{array}{l}\text { - } 8700 \text { Beverly Blvd., Los Angeles, } \\
\text { CA, USA } \\
\text { - Johns Hopkins University, } \\
\text { Baltimore, MD, USA }\end{array}$ \\
\hline 59 & $\begin{array}{l}\text { Immunoglobulin G Antibody } \\
\text { Immune Response Profile } \\
\text { Following Infection with } \\
\text { SARS-CoV-2 in COVID-19 } \\
\text { Egyptian Patients }\end{array}$ & Recruiting & COVID-19 & & $\begin{array}{l}\text { - Sohag University Hospital, } \\
\text { Sohag, Egypt }\end{array}$ \\
\hline 60 & $\begin{array}{l}\text { Efficacy and Safety of Early } \\
\text { COVID-19 Convalescent } \\
\text { Plasma in Patients Admitted for } \\
\text { COVID-19 Infection }\end{array}$ & Recruiting & $\begin{array}{l}\text { Severe acute respiratory } \\
\text { syndrome } \\
\text { coronavirus } 2\end{array}$ & $\begin{array}{l}\text { Biological: COVID-19 conva- } \\
\text { lescent plasma }\end{array}$ & $\begin{array}{l}\text { - Hospital Clínico Universidad } \\
\text { Católica, Santiago, Chile }\end{array}$ \\
\hline 61 & $\begin{array}{l}\text { Will Hydroxychloroquine Impede } \\
\text { or Prevent COVID-19 }\end{array}$ & Recruiting & $\begin{array}{l}\text { COVID-19 } \\
\text { Coronavirus } \\
\text { Coronavirus infections } \\
\text { SARS-CoV-2 }\end{array}$ & $\begin{array}{l}\text { Drug: Hydroxychloroquine-- } \\
\text { daily dosing } \\
\text { Drug: hydroxychloroquine-- } \\
\text { weekly dosing } \\
\text { Other: placebo oral tablet } \\
\text { Diagnostic test: monitoring } \\
\text { visit—baseline } \\
\text { Diagnostic test: monitoring } \\
\text { visit—week } 4 \\
\text { Diagnostic test: monitoring } \\
\text { visit—week } 8 \\
\text { Other: weekly assessment }\end{array}$ & $\begin{array}{l}\text { - Henry Ford Hospital, Detroit, MI, } \\
\text { USA } \\
\text { - Detroit Department of } \\
\text { Transportation (DDOT), Detroit, } \\
\text { MI, USA } \\
\text { - Detroit Fire Department \& Detroit } \\
\text { EMS, Detroit, MI, USA } \\
\text { - Detroit Police Department, } \\
\text { Detroit, MI, USA }\end{array}$ \\
\hline 62 & $\begin{array}{l}\text { Various Combination of Protease } \\
\text { Inhibitors, Oseltamivir, } \\
\text { Favipiravir, and } \\
\text { Hydroxychloroquine for } \\
\text { Treatment of COVID-19: a } \\
\text { Randomized Control Trial }\end{array}$ & $\begin{array}{l}\text { Not yet } \\
\text { recruiti- } \\
\text { ng }\end{array}$ & $\begin{array}{l}\text { SARS-CoV-2 infections } \\
\text { COVID-19 }\end{array}$ & Drug: oral & $\begin{array}{l}\text { - Assistant Professor Subsai } \\
\text { Kongsaengdao, Bangkok, } \\
\text { Thailand }\end{array}$ \\
\hline 63 & & Recruiting & COVID-19 & & $\begin{array}{l}\text { - Louis Mourier hospital (AP-HP), } \\
\text { Colombes, France }\end{array}$ \\
\hline
\end{tabular}


Table 1 (continued)

\begin{tabular}{|c|c|c|c|}
\hline No. & Title & Status & Conditions \\
\hline & $\begin{array}{l}\text { Predicting the Need for Intubation } \\
\text { in Hospitalised COVID-19 } \\
\text { Patients (PRED ICU COVID19) }\end{array}$ & & \\
\hline 64 & $\begin{array}{l}\text { Effects on the Qt Interval of } \\
\text { COVID-19 Coronavirus } \\
\text { Infection }\end{array}$ & Recruiting & $\begin{array}{l}\text { Coronavirus infection } \\
\text { Intensive care patients }\end{array}$ \\
\hline 65 & $\begin{array}{l}\text { COVID-19 Convalescent Plasma } \\
\text { for the Treatment of } \\
\text { Hospitalized Patients with } \\
\text { Pneumonia Caused by SARS- } \\
\text { CoV-2 }\end{array}$ & Recruiting & COVID-19 \\
\hline 66 & $\begin{array}{l}\text { COVID-19 Pandemic and } \\
\text { Worldwide Organ Procurement }\end{array}$ & Recruiting & COVID-19 \\
\hline 67 & $\begin{array}{l}\text { Testing the Accuracy of a Digital } \\
\text { Test to Diagnose Covid-19 }\end{array}$ & Recruiting & COVID-19 \\
\hline 68 & Clinical Trial of Allogeneic & Recruiting & COVID \\
\hline
\end{tabular}

Mesenchymal Cells from

Umbilical Cord Tissue in

Patients with COVID-19

69 The Heart Hive COVID-19 Study

70 National Survey of Symptoms of People Aged 70 and Overs Diagnosed with COVID-19

71 Seroconversion Among Staff at a Large Acute Care Hospital in Denmark During the COVID-19 Pandemic

72 Clinical Trial of Efficacy and Safety of Sinovac's Adsorbed COVID-19 (Inactivated)

Vaccine in Healthcare

Professionals
Interventions

Locations

Other: data monitoring for $48 \mathrm{~h}$ - Brabois Hospital (CHRU de within the first $12 \mathrm{~h}$ of admission for COVID-19 Nancy), Vandœuvre-lès-Nancy, France

- Servicio de Anestesia, Hospital General Universitario Gregorio Marañon, Madrid, Spain

Biological: COVID-19 conva- • Hospital of the University of lescent plasma Pennsylvania, Philadelphia, PA, USA

Diagnostic test: COVID-19 swab PCR test

- Paris Transplant Group, Paris, France

- King's College London, London, United Kingdom

Biological: mesenchymal cells • Hospital Universitario de Getafe, Drug: standard of care Getafe, Madrid, Spain

- Hospital Universitario de Cruces, Barakaldo, Spain

- Hospital Universitario de La Princesa, Madrid, Spain

- Hospital Infantil Universitario Niño Jesus, Madrid, Spain

- Hospital Ramón Y Cajal, Madrid, Spain

- Complejo Universitario La Paz, Madrid, Spain

Other: COVID-19 experience surveys

- Imperial College London, London, UK

Other: observation

- Angers University Hospital, Angers, France

Other: serial seroconversion measurements in hospital employees during the COVID-19 pandemic

Biological: adsorbed COVID-19 (inactivated) vaccine Biological: placebo
- Nordsjællands Hospital, Hillerød, Capital Region, Denmark

- Nykøbing Falster County Hospital, Nykøbing Falster, Southern Region, Denmark

- Universidade de Brasília, Brasilia, DF, Brazil

- Universidade Federal de Minas Gerais, Belo Horizonte, MG, Brazil

- Hospital das Clínicas da Universidade Federal do Paraná, Curitiba, PR, Brazil

- Hospital São Lucas da Pontificia Universidade Catolica do Rio Grande do Sul, Porto Alegre, RS, Brazil

- Hospital das Clínicas da UNICAMP, Campinas, SP, Brazil

- Hospital das Clínicas da Faculdade de Medicina de Ribeirão Preto da Universidade de São Paulo, Ribeirao Preto, SP, Brazil

- Instituto de Infectologia Emílio Ribas, Sao Paulo, SP, Brazil 
Table 1 (continued)

No. Title

Status

Conditions

Interventions

Locations

73 Gut Microbiota, "Spark and Flame" of COVID-19 Disease Antioxidant Therapy for COVID-19 Study

\section{Recruiting COVID-19}

Not yet

recruiti-

ng
Other: exposure

Dietary supplement: antioxidation therapy Other: standard of care
- Centro de Pesquisas Clínicas do Instituto Central do Hospital das Clínicas da Faculdade de Medicina da Universidade de São Paulo, Sao Paulo, SP, Brazil

- Instituto Israelita de Ensino e Pesquisa Albert Einstein, Sao Paulo, SP, Brazil

- Universidade Municipal de São Caetano do Sul, São Caetano do Sul, SP, Brazil

- Faculdade de Medicina de São José do Rio Preto - FAMERP, São José Do Rio Preto, São Paulo, Brazil

- Instituto de Infectologia Evandro Chagas - Fiocruz, Rio De Janeiro, Brazil

- Hospital CUF Infante Santo, S.A., Lisbon, Portugal

- Hospital de São Francisco Xavier, Lisbon, Portugal

- Centro Hospitalar Universitário São João, Oporto, Portugal

- Abia State Isolation Centre, Amachara, Umuahia, Abia State, Nigeria

- Benue State University Teaching Hospital, Makurdi, Benue State, Nigeria

- Brigadier Abba Kyari Memorial Hospital, Borno, Borno State, Nigeria

- University of Maiduguri Teaching Hospital, Maiduguri, Borno State, Nigeria

- University of Calabar Teaching Hospital, Calabar, Cross River, Nigeria

- Federal Medical Centre Idi-Aba, Abeokuta, Ogun State, Nigeria

- Olabisi Onabanjo University Teaching Hospital, Sagamu, Ogun State, Nigeria

- Infectious Disease Hospital, Amanawa, Sokoto State, Nigeria

- Murtala Muhammad Speciaist Hospital, Sokoto, Sokoto State, Nigeria

- Occupational Therapy Center, Sokoto, Sokoto State, Nigeria

- Usmanu Danfodiyo University Teaching Hospital, Sokoto, Sokoto State, Nigeria

Other: BioMedomics

- AO San Paolo, Milan, IT, Italy 
Table 1 (continued)

\begin{tabular}{|c|c|c|c|c|c|}
\hline No. & Title & Status & Conditions & Interventions & Locations \\
\hline & $\begin{array}{l}\text { Polymorphisms in Patients } \\
\text { (COST ACTION) }\end{array}$ & & & & \\
\hline 76 & $\begin{array}{l}\text { Experience of an Emergency } \\
\text { Intensive Care Unit During } \\
\text { COVID-19 Pandemic }\end{array}$ & Completed & COVID-19 & $\begin{array}{l}\text { Diagnostic test: COVID-19 di- } \\
\text { agnostic PCR }\end{array}$ & $\begin{array}{l}\text { - Seda Yilmaz Semerci, Istanbul, } \\
\text { Turkey }\end{array}$ \\
\hline 77 & $\begin{array}{l}\text { Inhaled Nitric Oxide for Preventing } \\
\text { Progression in COVID-19 }\end{array}$ & Recruiting & COVID-19 & Drug: nitric oxide & $\begin{array}{l}\text { - Tufts Medical Center, Boston, } \\
\text { MA, USA }\end{array}$ \\
\hline 78 & $\begin{array}{l}\text { Cohort of Patients Infected with } \\
\text { SARS-CoV2 (COVID-19) or } \\
\text { Suspected of Being }\end{array}$ & Recruiting & COVID-19 & Other: blood samples & $\begin{array}{l}\text { - GH Pitié-Salpêtrière / Service } \\
\text { d'Accueil des Urgences, Paris, } \\
\text { Ile- de-France, France }\end{array}$ \\
\hline 79 & $\begin{array}{l}\text { Hydrogen-Oxygen Generator with } \\
\text { Nebulizer in the Improvement of } \\
\text { Symptoms in Patients Infected } \\
\text { with COVID-19 }\end{array}$ & Recruiting & COVID-19 & $\begin{array}{l}\text { Device: oxyhydrogen } \\
\text { Device: oxygen }\end{array}$ & $\begin{array}{l}\text { - First Affiliated Hospital of } \\
\text { Guangzhou Medical University, } \\
\text { Guangzhou, Guangdong, China }\end{array}$ \\
\hline 80 & $\begin{array}{c}\text { Endovascular Thrombectomy in } \\
\text { COVID-19 Infected Patients }\end{array}$ & Completed & $\begin{array}{l}\text { Ischemic stroke } \\
\text { COVID-19 }\end{array}$ & $\begin{array}{l}\text { Other: mechanical } \\
\text { trombectomy }\end{array}$ & $\begin{array}{l}\text { - Uhmontpellier, Montpellier, } \\
\text { France }\end{array}$ \\
\hline 81 & $\begin{array}{l}\text { Pre-exposure Prophylaxis with } \\
\text { Hydroxychloroquine for High- } \\
\text { Risk Healthcare Workers During } \\
\text { the COVID-19 Pandemic }\end{array}$ & Suspended & COVID-19 & $\begin{array}{l}\text { Drug: hydroxychloroquine } \\
\text { Drug: placebos }\end{array}$ & - ISGlobal, Barcelona, Spain \\
\hline 82 & $\begin{array}{l}\text { Evaluating Clinical Parameters of } \\
\text { COVID-19 in Pregnancy }\end{array}$ & $\begin{array}{l}\text { Not yet } \\
\text { recruiti- } \\
\text { ng }\end{array}$ & $\begin{array}{l}\text { COVID-19 } \\
2019 \text { novel coronavirus } \\
\text { infection } \\
\text { COVID-19 infection }\end{array}$ & & $\begin{array}{l}\text { - Chelsea and Westminster } \\
\text { Hospital NHS Foundation Trust, } \\
\text { London, UK }\end{array}$ \\
\hline 83 & $\begin{array}{l}\text { Characteristics of COVID-19 } \\
\text { Infection Among PREGnant } \\
\text { Women }\end{array}$ & Recruiting & $\begin{array}{l}\text { Coronavirus infection } \\
\text { Pregnancy related }\end{array}$ & $\begin{array}{l}\text { Other: COVID-19 positive via } \\
\text { testing }\end{array}$ & $\begin{array}{l}\text { - INOVA Health System, Falls } \\
\text { Church, VA, USA }\end{array}$ \\
\hline 84 & $\begin{array}{l}\text { Combination of Chest } \\
\text { Scanography and Nasal Viral }\end{array}$ & $\begin{array}{l}\text { Active, not } \\
\text { recruiti- }\end{array}$ & $\begin{array}{l}\text { COVID-19 } \\
\text { SARS-CoV-2 }\end{array}$ & & $\begin{array}{l}\text { - Uh Montpellier, Montpellier, } \\
\text { France }\end{array}$ \\
\hline
\end{tabular}

Detection Test to Detect

COVID-19 Positive Patients

Before Surgical Intervention in a University Hospital During

Coronavirus Pandemia

85 Implementation of Physiotherapy on COVID-19 Patients in ICU

86 Tableted COVID-19 Therapeutic Vaccine

87 Effects of COVID-19

Convalescent Plasma (CCP) on

Coronavirus-Associated

Complications in Hospitalized

Patients

88 Kerecis Oral and Nasal Spray for

Treating the Symptoms of COVID-19

89 Anti COVID-19 Convalescent Plasma Therapy

90 Influence of COVID-19 Infection in Thromboembolic Venous Disease: National Cohort Study

91 Elmo Respiratory Support Project COVID-19 ng

Recruiting SARS-CoV-2

COVID-19

Active, not COVID-19

recruiti-

ng

Recruiting COVID-19

SARS-CoV-2

Recruiting COVID-19

Not yet

recruiti-

COVID-19

ng

Not yet

recruiti-

ng

Not yet

recruiti- Respiratory failure with

ng hypoxia
COVID-19

COVID-19
Other: physiotherapy

Biological: V-SARS

Uhmontpellier, Montpellier, France

- Immunitor Inc., Vancouver, BC British Columbia, Canada

- Aldar Bourinbayar, Ulaanbaatar, BZD, 3-khoroo, Mongolia

Biological: COVID-19 conva- - San Francisco General Hospital, lescent plasma (CCP) San Francisco, CA, USA

Biological: placebo

- UCSF Medical Center at Mount Zion, San Francisco, CA, USA

- University of California, San Francisco Medical Center (Parnassus Campus), San Francisco, CA, USA

Device: Kerecis oral and nasal spray

Other: placebo

- National Hospital of Iceland (Landspítali), Reykjavík, Iceland

Biological: anti-SARS-CoV-2 convalescent plasma

Other: deep venous disease diagnostic

- Red de Investigacion Vascular (SEACV), Madrid, Spain

Other: Elmo Project at

COVID-19: study in humans 
Table 1 (continued)

\begin{tabular}{|c|c|c|c|c|c|}
\hline No. & Title & Status & Conditions & Interventions & Locations \\
\hline 92 & $\begin{array}{l}\text { Convalescent Plasma vs Human } \\
\text { Immunoglobulin to Treat } \\
\text { COVID-19 Pneumonia }\end{array}$ & Recruiting & COVID-19 pneumonia & $\begin{array}{l}\text { Device: Elmo Project at } \\
\text { COVID-19: proof of concept } \\
\text { and usability } \\
\text { Drug: plasma from COVID-19 } \\
\text { convalescent patient } \\
\text { Drug: human immunoglobulin }\end{array}$ & $\begin{array}{l}\text { - Centenario Hospital Miguel } \\
\text { Hidalgo, Aguascalientes, } \\
\text { Mexico }\end{array}$ \\
\hline 93 & $\begin{array}{l}\text { Observational Cohort of } \\
\text { COVID-19 Patients at } \\
\text { Raymond- Poincare }\end{array}$ & Recruiting & COVID-19 & & $\begin{array}{l}\text { - Department of Infectiology, } \\
\text { Raymond Poincaré Hospital, } \\
\text { APHP, Garches, France }\end{array}$ \\
\hline 94 & $\begin{array}{l}\text { Longitudinal Energy Expenditure } \\
\text { and Metabolic Effects in Patients } \\
\text { with COVID-19 } \\
\text { (LEEP-COVID) }\end{array}$ & Recruiting & COVID-19 & $\begin{array}{l}\text { Device: Q-NRG Metobolic } \\
\text { Cart Device } \\
\text { Device: MuscleSound } \\
\text { Ultrasound } \\
\text { Device: multifrequency } \\
\text { bioimpedance spectroscopy }\end{array}$ & $\begin{array}{l}\text { - Duke University Medial Center, } \\
\text { Durham, NC, USA }\end{array}$ \\
\hline 95 & $\begin{array}{l}\text { Part Two of Novel Adoptive } \\
\text { Cellular Therapy with SARS- } \\
\text { CoV-2 Specific T Cells in } \\
\text { Patients with Severe COVID-19 }\end{array}$ & Recruiting & COVID-19 & $\begin{array}{l}\text { Biological: SARS-CoV-2 spe- } \\
\text { cific T cells }\end{array}$ & $\begin{array}{l}\text { - Changi General Hospital, } \\
\text { Singapore, Singapore } \\
\text { - KK Women's and Children's } \\
\text { Hospital, Singapore, Singapore } \\
\text { - National University Hospital, } \\
\text { Singapore, Singapore } \\
\text { - Sengkang General Hospital, } \\
\text { Singapore, Singapore } \\
\text { - Singapore General Hospital, } \\
\text { Singapore, Singapore }\end{array}$ \\
\hline 96 & $\begin{array}{l}\text { A Study Evaluating the Efficacy } \\
\text { and Safety of High-Titer } \\
\text { Anti-SARS-CoV-2 Plasma in } \\
\text { Hospitalized Patients with } \\
\text { COVID-19 Infection }\end{array}$ & Recruiting & COVID-19 & $\begin{array}{l}\text { Biological: anti-SARS-CoV-2 } \\
\text { convalescent plasma }\end{array}$ & $\begin{array}{l}\text { - Froedtert Hospital, Milwaukee, } \\
\text { WI, USA }\end{array}$ \\
\hline 97 & $\begin{array}{l}\text { Identification of Predictors for the } \\
\text { Evolution of COVID-19 Related } \\
\text { Pneumonia by Transcriptomic } \\
\text { and Seroproteomic }\end{array}$ & Recruiting & $\begin{array}{l}\text { COVID-19 } \\
\text { interstitial pneumonia }\end{array}$ & & $\begin{array}{l}\text { - IRCCS Policlinico San Donato, } \\
\text { San Donato Milanese, MI, Italy }\end{array}$ \\
\hline 98 & $\begin{array}{l}\text { CORonavirus (COVID-19) } \\
\text { Diagnostic Lung UltraSound } \\
\text { Study }\end{array}$ & $\begin{array}{l}\text { Not yet } \\
\text { recruiti- } \\
\text { ng }\end{array}$ & COVID-19 & Diagnostic test: lung ultrasound & \\
\hline 100 & $\begin{array}{l}\text { Convalescent Plasma (PC) and } \\
\text { Human Intravenous } \\
\text { Anti-COVID-19 } \\
\text { Immunoglobulin (IV Anti } \\
\text { COVID-19 IgG) in Patients } \\
\text { Hospitalized for COVID-19 } \\
\text { Safety and Efficacy of Tramadol in } \\
\text { COVID-19 Egyptian Patients }\end{array}$ & $\begin{array}{l}\text { Not yet } \\
\text { recruiti- } \\
\text { ng }\end{array}$ & $\begin{array}{l}\text { Coronavirus disease } \\
2019 \text { (COVID-19) }\end{array}$ & $\begin{array}{l}\text { Biological: COVID-19 conva- } \\
\text { lescent plasma } \\
\text { Biological: anti-COVID-19 hu- } \\
\text { man immunoglobulin } \\
\text { Drug: standard (specific) thera- } \\
\text { py for COVID-19 } \\
\text { Drug: tramadol } \\
\text { Other: standard care delivered } \\
\text { in the isolation hospitals }\end{array}$ & $\begin{array}{l}\text { - LifeFactors Zona Franca SAS, } \\
\text { Medellín, Antioquia, Colombia }\end{array}$ \\
\hline
\end{tabular}

COVID-19 patients, including plasma therapy. Recently, convalescence plasma therapy in which the immunoglobulin of cured COVID-19 patients is injected into a severe patient as a treatment option is explored in India, China, and the USA. Table 1 shows the status of recent clinical trials of vaccines against SARS-CoV-2 infection. Table 2 shows the current status of the clinical trials of vaccines and candidate therapy for cytokine release syndrome (CRS) against SARS-CoV-2 infection.

\section{Immune Catastrophe in the Panic of Self-Defense}

The immune response is a strong defense against invasive pathogens. Recent studies demonstrated an acute inflammation in the severely affected COVID-19 patients, leading to cytokine storm, acute respiratory distress, and then multiple organ failure. Nutritional interventions including vitamin $\mathrm{C}$ and $\mathrm{D}$ and antioxidants are also used to boost the immune 
Table 2 Current status of the clinical trials of vaccines and candidate therapy for cytokine release syndrome (CRS) against SARS-CoV-2 infection (Source: National Institute of Health, https://clinicaltrials.gov/) Accessed on Aug 1, 2020

\begin{tabular}{|c|c|c|c|}
\hline Company & Approach & Stage & Strategy \\
\hline $\begin{array}{l}\text { Arcturus } \\
\text { Therapeutics }\end{array}$ & Vaccine & Phase $1 / 2$ & $\begin{array}{l}\text { Engineering } \\
\text { RNA with } \\
\text { nanoparticle }\end{array}$ \\
\hline BioNTech & Vaccine & Phase 3 & mRNA \\
\hline Zydus Cadila & $\begin{array}{r}\text { ZyCoV-D } \\
\text { vaccine }\end{array}$ & Phase $1 / 2$ & $\begin{array}{l}\text { RNA } \\
\text { recombinant } \\
\text { measles virus }\end{array}$ \\
\hline $\begin{array}{l}\text { Mudoch Childre's } \\
\text { Research } \\
\text { Institute }\end{array}$ & $\begin{array}{l}\text { BCG } \\
\text { vaccine }\end{array}$ & Phase $2 / 3$ & $\begin{array}{l}\text { Live attenuated } \\
\quad \text { virus }\end{array}$ \\
\hline $\begin{array}{l}\text { Medicago, GSK, } \\
\text { Dynavax }\end{array}$ & $\begin{array}{l}\text { Plant-based } \\
\text { vaccine }\end{array}$ & Phase 1 & $\begin{array}{r}\text { Virus-like } \\
\text { particle }\end{array}$ \\
\hline CureVac & Vaccine & Phase 1 & $\begin{array}{c}\text { Man-made } \\
\text { mRNA }\end{array}$ \\
\hline Eli Lilly & Treatment & Phase 3 & $\begin{array}{l}\text { Antibody } \\
\text { treatment }\end{array}$ \\
\hline $\begin{array}{l}\text { GlaxoSmithkline+ } \\
\text { Clover } \\
\text { Biopharmaceuti- } \\
\text { cals }\end{array}$ & Vaccine & Phase 1 & $\begin{array}{l}\text { Engineering } \\
\text { adjuvants with } \\
\text { proteins }\end{array}$ \\
\hline $\begin{array}{l}\text { Inovio } \\
\quad \text { Pharmaceuticals }\end{array}$ & Vaccine & Phase 1 & DNA vaccine \\
\hline Johnson \& Johnson & $\begin{array}{r}\text { Vaccine and } \\
\text { treatment }\end{array}$ & Phase $1 / 2$ & Deactivated virus \\
\hline Pfizer-BioNTech & $\begin{array}{r}\text { Vaccine and } \\
\text { treatment }\end{array}$ & Phase $2 / 3$ & $\begin{array}{l}\text { Has not yet } \\
\text { revealed } \\
\text { strategy, } \\
\text { five-point plan } \\
\text { released } \\
\text { RNA vaccine }\end{array}$ \\
\hline $\begin{array}{l}\text { Regeneron } \\
\text { Pharmaceuticals }\end{array}$ & Treatment & Phase 3 & $\begin{array}{l}\text { Cocktail of } \\
\text { antibodies }\end{array}$ \\
\hline Sanofi & $\begin{array}{r}\text { Vaccine and } \\
\text { treatment }\end{array}$ & Phase 3 & $\begin{array}{l}\text { Chimera of RNA } \\
\text { viruses, } \\
\text { Kevzara drug }\end{array}$ \\
\hline Takeda & Treatment & Treatment phase & $\begin{array}{l}\text { Plasma of treated } \\
\text { patients }\end{array}$ \\
\hline Vir Biotechnology & Treatment & Phase 1 & $\begin{array}{l}\text { Viral replication } \\
\text { inhibitor }\end{array}$ \\
\hline Ascletis Pharma & Treatment & Phase $1 \mathrm{~b}$ & $\begin{array}{l}\text { Cocktail of } \\
\text { danoprevir and } \\
\text { titonavir }\end{array}$ \\
\hline $\begin{array}{l}\text { Gamaleya Institute } \\
\text { of Epidemiology } \\
\text { and } \\
\text { Microbiology }\end{array}$ & Vaccine & Phase 2 & Isolated strain \\
\hline $\begin{array}{l}\text { Siberian Vector } \\
\text { Institute }\end{array}$ & Vaccine & Phase 1 & $\begin{array}{l}\text { Using a platform } \\
\text { first developed } \\
\text { for Ebola }\end{array}$ \\
\hline $\begin{array}{l}\text { Moderna } \\
\text { Therapeutics }\end{array}$ & Vaccine & Phase 3 & $\begin{array}{l}\text { RNA vaccine } \\
\text { (mRNA } \\
-1273)\end{array}$ \\
\hline CanSino Biologics & Vaccine & To start phase 3 & $\begin{array}{l}\text { SARS-CoV-2 } \\
\text { genetic code }\end{array}$ \\
\hline
\end{tabular}

Table 2 (continued)

\begin{tabular}{llll}
\hline Company & Approach & Stage & Strategy \\
\hline & & & $\begin{array}{c}\text { entwined in } \\
\text { harmless virus } \\
\text { Non-replicating } \\
\text { virus }\end{array}$ \\
Gilead Sciences & Treatment & Phase 3 & $\begin{array}{c}\text { Remdesivir } \\
\text { Oxford University }\end{array}$ \\
& Vaccine & $\begin{array}{c}\text { Phase 2/3 trial in } \\
\text { UK, phase 3 }\end{array}$ & $\begin{array}{c}\text { AZD 1222 } \\
\text { Non-replicating } \\
\text { trials in SA }\end{array}$ \\
& & and Brazil & COVAXIN \\
Bharat Biotech & Vaccine & Phase 1/2 & COnactivated \\
& & & virus \\
\hline
\end{tabular}

response against this disease. After the recent demonstration of the crystal structure of spikes in SARS-CoV-2 [64], several opportunities had emerged for the development of a vaccine for COVID-19 treatment. The S protein in the spike of SARS$\mathrm{CoV}-2$ is the major target for vaccine development, and several companies are now in the advancing stage of an effective therapeutic strategy against SARS-CoV-2. Figure 3 shows the proposed treatment strategies targeting ACE2 receptors and the receptor-binding domain (RBD) of the spike for designing a promising drug therapy against COVID-19.

\section{Proposed Hypothesis}

We propose a "Pitchfork self-defense hypothesis" where a varied and wide range of effects are observed among the infected population from mild symptoms to multiorgan failure leading to death. This all is owing to the flawed genome and incompetent immune system which acts as a rod for its own back in the rage of self-defense. The peculiar aspect is the reckless and speedy multiplication of virus resulting in the accumulation of monstrous viral copies which in turn calls for a "save the ship" signal activation. The defense system, sensing this as a hulking danger, apparently must be reacting in an exaggerated manner, deploying and marching its armed forces to the site of infection in the form of the cytokine storm syndrome. This storm would do more harm than good, engulfing the healthy RBCs and WBCs, and further inviting more of the type to the site of infection. Thus, this likely stimulates the blood vessels to leak out the immune cells in adjoining tissues, pouring fluid into the lungs. This pneumonia-like condition undoubtedly must be activating cell suicide in lung tissue and hence tearing off the alveoli. Air sacs failing to exchange gases would lead to chronic oxygen starvation which finally culminates in respiratory distress. Thus, in almost $100 \%$ of cases, the first critical clinical sign is respiratory unrest which fits in the said hypothesis perfectly. Once the blood vessels lose their fluid, a sudden drop in blood 


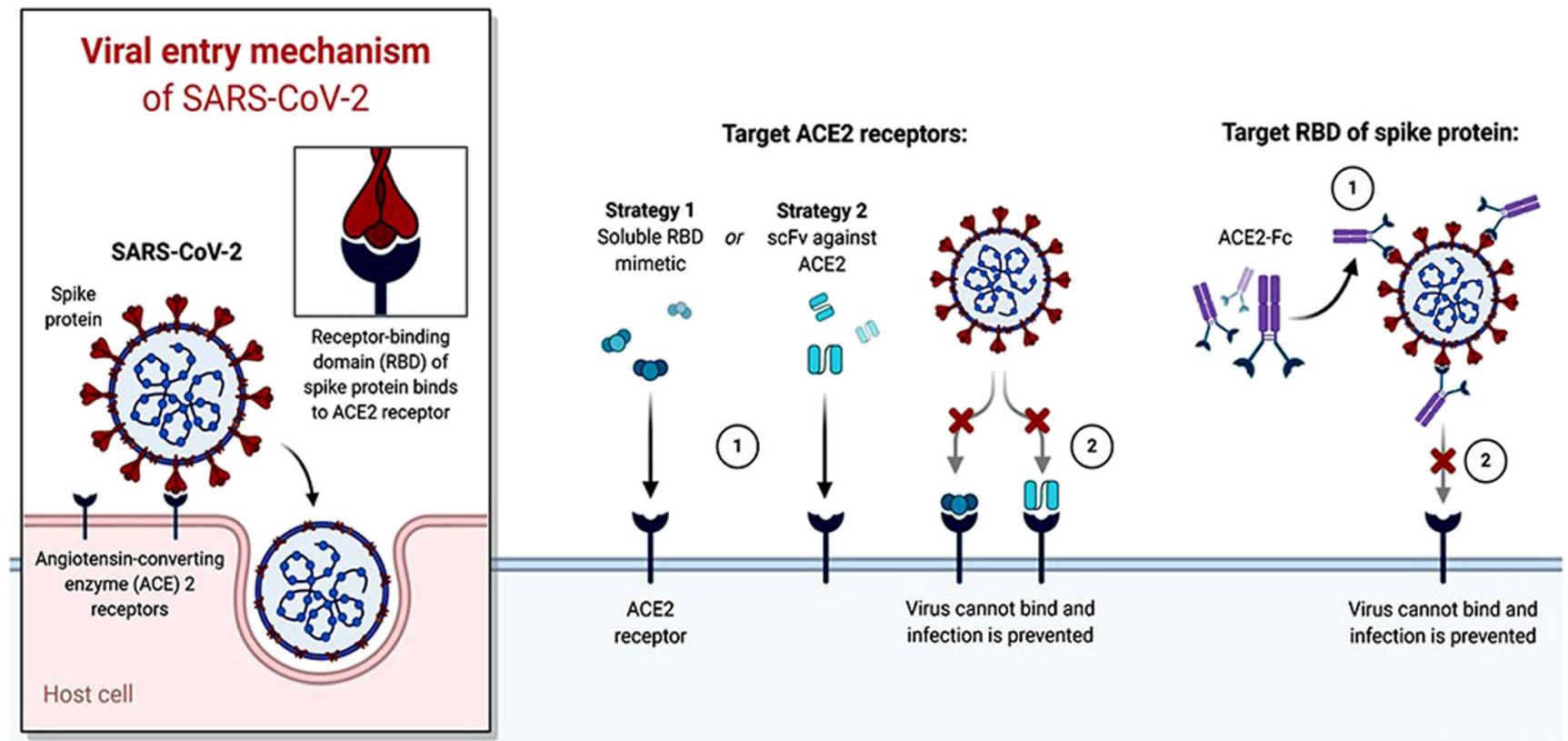

Host cell

Fig. 3 Demonstration of viral entry mechanisms and proposed therapeutic strategies against SARS-CoV-2. It uses human ACE2 receptor for entering the host cell by binding its surface spike protein mediated through proteolytic enzyme activity and receptor-binding domain (RBD). The RBD shows strong hACE2 binding affinity allowing SARS-CoV-2 to befool the host defense mechanism pressure is observed. This may probably be causing clogging of blood vessels and clotting of blood in several tissues leading to a shortage of blood supply and oxygen to the vital organs. This expectedly would have a shocking climax of multiple organ failure. But, interestingly, not all individuals meet with the same fate. Moreover, there are different categories into which individuals can be divided into, as follows: (1) extremely vulnerable category which includes people with an impaired immune system, a chronic respiratory condition, cancer, etc. who cannot afford a competent immune response and are sure to succumb to the disease; (2) high-risk category which includes old people, pregnant women, obese people, and diabetic patients, who are highly susceptible owing to low immunity; and (3) low-risk category which includes healthy and younger individuals who are well equipped to give a tough fight. Frontline workers (mainly doctors, workers, and police personnel) remain in the high-exposure zone and so have a greater chance of contacting COVID-19. Unreasonable and hectic service schedules make the fall prey to the virus since a tired and restless body temporarily loses on its immunity. But there are also reports where young, healthy, and shielded individuals were victimized to death due to COVID-19. The abnormal immune system rests on a faulty genome; thus, the strongest are selected and the defective perish. This can be explained with the present hypothesis in the sense that some immune defects remain latent and are expressed only when a virus triggers them. In the first few days of catching any infection majorly, natural killer cells and macrophages take charge in containing the pathogen and preventing against any severe damage in the body. In case these fail to fight out the infection, then B and T lymphocytes come in the picture and rage a stronger defense response [65]. People with impaired immune systems are more vulnerable to severe infections. Many evidences support this view. (1) One of the most buttressing exemplar is that patients having impaired perforins (perforinopathies) tend to trigger a very severe cytokine storm. These perforins are stocked in natural killer cells and cytotoxic T lymphocytes. Since perforins are glycoproteins that are critically responsible for pore formation in the host cell (infected with virus) causing immune cellmediated death of the target cell, thus, reduced attenuated expression of perforins invites a cytokine storm. Thus, if such patients are provided with sufficient amounts of perforin, then it may help generate a healthy immune response against SARS-CoV-2 infection. (2) Also IL-6 blocks the expression of granzyme B and perforins and prevents the killing of the viral-infected cell (experimentation studies on mice). Therefore, it is of concern to note that in COVID-19 patients succumbing to heart attack, IL-6 prevented the activity of STAT-5 signal transducer, thereby decreasing perforin levels. Thus, a treatment involving anti IL-6R would be quite effective against COVID-19 infection. In a nutshell, patients with weakened immune systems tend to show severe symptoms because of elevated levels of IL- 6 mediated by poor perforin functionality [66]. It has been discovered by the Indo-US research team that the Indian population is better equipped with these killer cell immunoglobulin-like receptor genes (KIR genes) and therefore can contain the infection in the initial 
stage itself. Thus, Indian populations are less susceptible to these infections and also confer Indians with stronger immunity against other viruses, autoimmune diseases, and even tumors [67]. However, recently, this claim was opposed and declared baseless by a few science researchers and science magazine editors [68]. Thus, the answer lies in developing artificial adaptive immunity through an effective medicine.

Genome Analysis/Genomics Could Help Resolve Some Unanswered Questions A comprehensive genome analysis of the virus as well as the host population to predict genetic determinants is the need of the hour. Such a large-scale collaborative task of genome sequencing may unmask hidden mysteries like severity and susceptibility of COVID-19. Many such initiatives using high-throughput sequencing technologies are in the pipeline (namely Genomics England, UK Biobank). Since we know that genome is unique to an individual and it is the sole dower of phenotypic or functional expression of a trait, so it is imperative to first analyze the defect at the molecular level. This would open a gamut of doors for therapeutic and preventive strategies and may help answer all the puzzles concerning COVID-19. Once we know the gene, we may easily correlate any defect in its protein expression and biochemical pathway concerning the disease. This gene structure would also give an insight into new and ameliorating drugs and therapies.

\section{Current Therapeutic Strategies for the Development of an Effective Vaccine Against COVID-19}

In this hour of COVID-19 pandemic, a population of 7.8 billion can be safeguarded only by active immunity. Natural active immunity cannot be expected from the diseased chunk of the population supporting a fragile immune system. Also, isolation alone cannot help, since it is not an indelible solution. Thus, developing an effective vaccine is utmost required to develop adaptive immunity to fight upcoming viral infections. Thus, today, countries vie with each other for developing an effective vaccine against SARS-CoV-2. To date, approximately 100 designs of different vaccines have been proposed worldwide and more than six groups of these vaccines have already undergone trial (Fig. 4).

\section{Angiotensin-Converting Enzyme-2 (ACE-2) Receptor-Viral} Doorknob-Based Therapy Dozens of pharmaceutical companies are targeting this key to unlock a SARS-CoV-2 vaccine. Different strategies are being worked upon. It was recently discovered that ACE receptors are present not only on lung, heart, gut, and kidney cells but also on the nose. Using ACE receptors in therapeutics holds a contrasting version. Some research teams undermine its potentials citing that non- steroidal inflammatory drugs may spoil the show by increasing the expression of ACE receptors, while others emphasize that using a floating enzyme strategy may prove effective. These ACE receptor mimics may befool viruses and make them latch on (Apeiron Biologics, an Austrian pharmaceutical company). We propose that a gene variation study of the ACE-2 gene specific to lung tissue can be instrumental in discovering effective drugs against viral entry since this gene deals with the production of surfactant for the lungs. Any defect or overexpression of this gene may either prevent viral entry into the host cell or may make it detrimental for the host. One such research to support our proposal is the CCR5 gene on blood cells. Genetic analysis revealed that people with defective CCR5 gene prevented HIV from entering the host cell [69]. Thus, in this case, a defective gene was at an advantage since it made some people immune to HIV infection by preventing viral entry. One of the observed trends in COVID19 is the cytokine storm (similar to the one observed in H1N1 flu). This also results from some impaired gene which causes a hyperexpressive immune response. Thus, a genetic variation study among populations would help figure out who is less vulnerable and who is more prone to such deadly viruses. The viral genomics and proteomics studies would help to discover some relevant transcription factors that induce overexpression of the host immune system. In a recent proteomics study of SARS-CoV-2-infected host cells, a fresh understanding of some gene therapies effective against COVID-19 was hinted. It includes the modulations in the host cell pathway infected with SARS-CoV-2 in human cell culture studies and suggests that effective therapy can be blocking these pathways by some inhibitor molecules that would halt the process of viral multiplication.

MicroRNA, a Direct Attack on the Viral Genome The miRNAs are small, non-coding, single-stranded RNA molecules, which are known to modulate a variety of vital physiological processes including RNA silencing, post-transcriptional regulators of gene expression involved in cardiovascular development and health [70-75]. Several thousand human genes, amounting to about one third of the whole genome, are potential targets for regulation by the several hundred miRNAs encoded in the genome [76]. It is evident from the previous studies that novel miRNAs can be used as promising tools as diagnostic biomarkers and therapeutic drug targets for several diseases [77-79]. In the present context, microRNAs specifically mitochondrial microRNA can prove as a panacea. Silico analysis studies have been used to interpret which host microRNAs have complete complementarity with viral RNA so that viral RNA expression can be silenced.

Recently, microRNA-5197-3p has been identified as the most valuable site for interaction with SARS-CoV-2, and complete complementary miRNA regions in the viral genome have been predicted. This proposed site lacks any side effect 


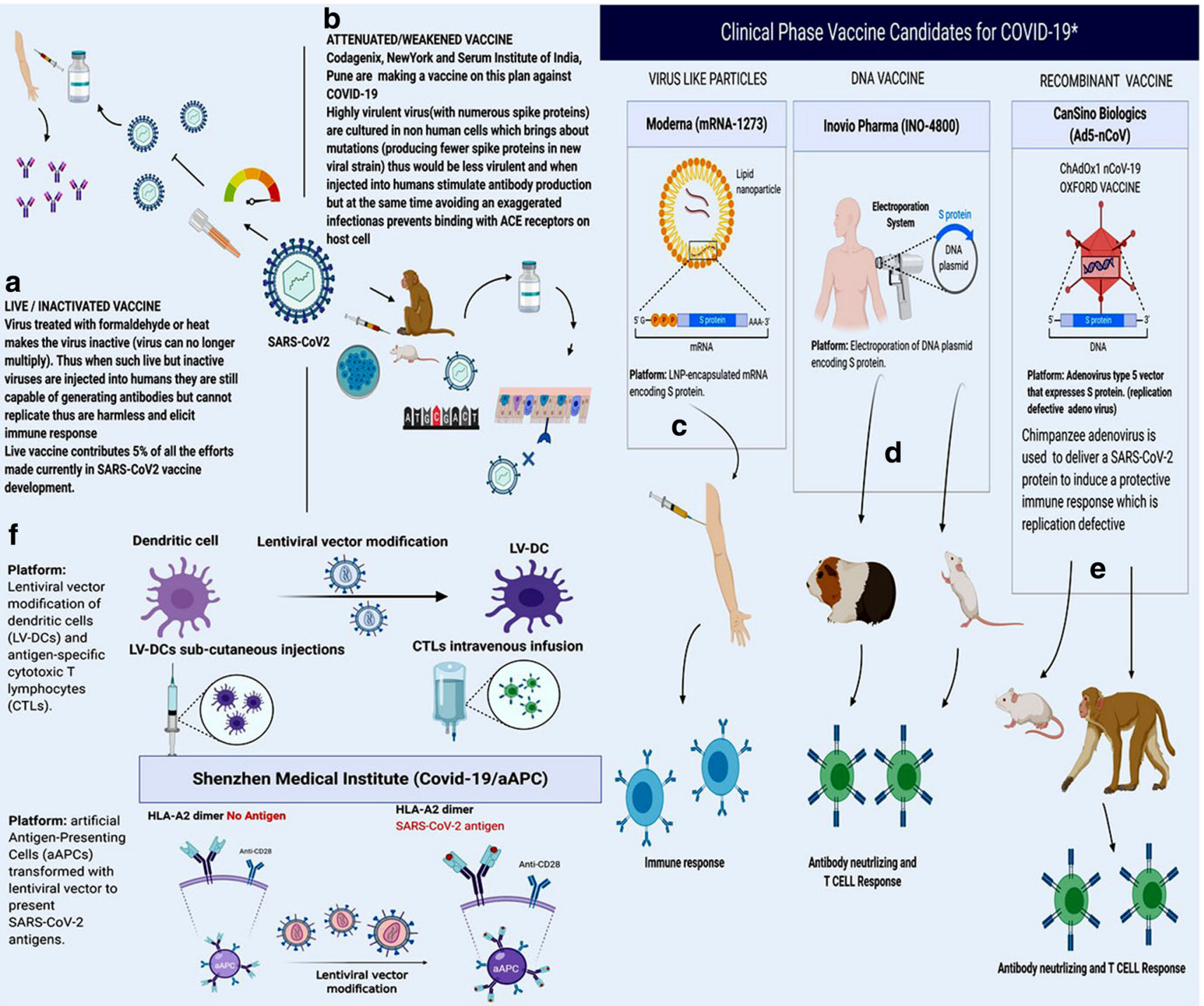

Fig. 4 A-F Possible therapeutic strategies for the development of an effective vaccine against SARS-CoV-2

or competition and a synthetic microRNA constructed based on this template may act as a remarkable candidate for the treatment of COVID-19. These may then be packed into exosomes and either injected into the blood for multiple organ treatment or simply inhaled into the lungs through nebulizers. Antiviral miRNAs present in the host target specific genes of the virus and interfere with viral molecular processes vital for reproduction, namely replication, protein synthesis, and phenotypic expression. Thus, microRNAs are vital tools for tailoring and silencing viral genome as these complementarily bind to the viral genome and prevent their expression. It has been found that hsa-miR-27b is uniquely specific to only SARS-CoV-2 found in India, and so, Indian populations are naturally endowed with a miraculous antidote to this virus. Alnylam and Vir, two big companies, are working on temporarily silencing the ACE2 receptors using interference RNA technology. They believe that when there will be no receptors, then viruses would not be able to enter. But another big challenge is delivering these RNA molecules to the target site. It has been proposed that these microRNA would probably be packed in fat vesicles and inhaled in the form of a dry powder. But most researchers are skeptical about this as knocking down these vital blood pressure-regulating receptors may prove fatal. To speed up the emergency medical need of vaccines and therapies against COVID-19, the Food and Drug Administration (FDA) of the USA has provided fast-track designation to Mrna Vaccine mRNA-1273 created by Moderna. It is in phase II of the clinical trial. Moderna is highly trusted as earlier it could fast-track the Zika vaccine.

Recombinant Vaccine It is a recombinant adenovirus vaccine developed by the University of Oxford. ChAdOx $1 \mathrm{nCoV}-19$ has been genetically engineered using weakened common cold adenovirus (ChAdOx1) infective only to chimpanzees. Genes coding for spike glycoprotein (S) of SARS-CoV-2 virus have been inserted into these viruses as these spike 
proteins are vital to bind on to ACE2 receptors on human cells. Its peculiar feature is that MenACWY has been used as an active control instead of saline solution. It gave very encouraging positive results on monkeys, generating antibodies within 28 days of its administration. It also drastically reduced respiratory distress in the patients and also prevented viral replication. Its human trials are in the process, and the university has already signed an agreement for its global manufacture and sale with Astra Zeneca. It is under trial on humans and is estimated that the initial study would include more than 1100 healthy subjects between 18 and 55 years of age. Exclusion criteria include pregnant, breastfeeding mothers and COVID-19 patients.

Epitope-Based Vaccines The coronavirus has spike proteins on its shell which are essential to latch on to the host cellular receptors. Viruses have been smart enough to evade the host's defense system by hiding their receptor binding motif (RBM). Thus, one of the strategies could be to design a vaccine targeting the RBM of SARS-CoV-2 virus. Tel Aviv University (TAU) of Israel is working on the same plan in association with Neovii, a pharmaceutical company. They aim to come up with a COVID-19 epitope vaccine based on in silico or computational prediction. It will be a cost-effective solution with great therapeutic efficacy.

Drug Against Cytokine Storm The National Institutes of Health (NIH), USA, has sponsored a biotechnology company, CytoAgents, to fast-track the production of GP1681. This would be effective in controlling the cytokine storm resulting from the SARS-CoV-2 infection. These are small molecules known to show a host-directed methodology to spot the fundamental reason of cytokine storm, altering the host's natural immune system. This molecule would be effective against other viral diseases like influenza. It is currently under phase I and II of the human trial. There are enough case studies that have reported an exaggerated and abnormal production of IL-6 that led to "cytokine storm" and which finally ended up in heart failure due to stimulation of the coagulation process. Also, tissue necrosis and infiltration of monocytes and macrophages are commonly observed in both COVID-19 patients showing severe symptoms and postmortem pathological analysis. The authors propose that there is a good possibility that anti-interleukin-6 (IL-6) therapy may manage COVID-19-induced cytokine storm (hemophagocytic lymphohistiocytosis, macrophage activation syndrome, and sepsis) [80]. Cytokines IL-6, IL-2, IL-1 $\beta$, IL-8, IL-17, IL-10, and IL-4 all have known to increase excessively during COVID-19. Tocilizumab is a human monoclonal anti-IL-6 receptor antibody, extracted from patients with cytokine release syndrome. This is in phase 4 for SARS-CoV-2 trial. Tocilizumab can be associated with soluble IL-6R and mIL-6R, and inhibit signal transduction. However, it is a very costly treatment and its safety risks need to be tested in clinical trials [80-82].
Adjuvant Vaccine for COVID-19 Adjuvant is generally a chemical/drug or immunological agent added to a vaccine in small amounts to increase the production of antibodies. Thus, an adjuvant vaccine would probably provide instant and longlasting immunity. GlaxoSmithKline and Sanofi Pasteur (French Pharma-Company) together are working on the development of an adjuvant vaccine against SARS-CoV-2.

Synthetic Chimeric COVID-19 Vaccine Reconstruction of live synthetic less virulent SARS-CoV-2 virus which may provide vaccine protection against COVID-19 is in the pipeline. This commendable project is being taken up by Tonix Pharmaceuticals which had earlier developed the horsepox virus vaccine on a similar plan. University of Alberta, Canada, has signed a licensing agreement with Tonix Pharmaceuticals. Their basic plan is to synthesize some antigen genes of SARS-CoV-2 to innervate T cell immune response. They have a license to create 3 vaccines for COVID-19, namely TNX-1810, TNX-1820, and TNX-1830. Currently, it is at the pre-investigation of new drug stage. This kind of vaccine no doubt can prove miraculous but at the same time may instigate certain criminal minds to construct deadly bioweapons.

Emetine Injections National Center for Advancing Translational Sciences (NCATS) and Acer Therapeutics (pharmaceutical company) have agreed on placebocontrolled and random tests of this antiviral drug on COVID-19 patients.

NVX-CoV2373 Vaccine The Coalition for Epidemic Preparedness Innovations (CEPI) has agreed to fund $\$ 384 \mathrm{~m}$ to Novavax for manufacturing Matrix-M adjuvant and NVXCoV2373 vaccine antigen of COVID-19 vaccine which would boost rapid production of antibodies.

Antibody Cocktail COVI-SHIELD Some researchers at Mount Sinai Health System have come up with the idea of developing a triple-antibody prophylactic and therapy. This antibody cocktail specifically would safeguard frontline workers and doctors who are frequently exposed to this virus They aim at screening approximately 1500 COVID-19 recovered patients for identifying and isolating at least 3 vital antibodies against spike proteins of SARS-CoV-2 virus from their blood plasma. Then, monoclonal antibodies would be synthesized in collaboration with Sorrento Therapeutics. This would specifically provide immunity to the high-risk population for at least 2 months. This therapy may also provide resistance to future virus mutations and is currently filing an Investigational New Drug (IND) application.

Novel Decoy Cellular Vaccine Transgenic antigen-expressing cells: In this innovative strategy, nonreplicating, irradiated cells 
(I-cells) would be deployed as presenting carriers of antigens of SARS-Cov-2 so that these can be recognized by the host immune cells. These are irradiated to prevent in vivo replication and will act as a vaccine to protect against COVID-19 disease. It is thus a transgenic antigen-expressing cell.

ACCORD program Official records depict that the UK was worst affected by the COVID-19 pandemic; thus, the UK government has constituted an Accelerating COVID-19 Research \& Development (ACCORD) Program to step up large-scale research and development strategies to fight COVID-19. The first drug has been fast-tracked is bemcentinib. This drug is a selective inhibitor of the AXL kinase protein and was originally developed to prevent cancer cell metastasis. It has been proposed to use this drug against SARS-CoV-2 since this virus uses AXL kinase protein for its entry into the host cell. Thus, by inhibiting this protein, the virus can be prevented from infecting cells. This drug is a panacea and has also proven effective against the Ebola and Zika viruses. Another important characteristic of this drug is that it is safe in case of adults as its target is a protein that is least essential in adulthood. This drug can prevent the virus from both entering the host cell in the first stage and controlling the progression of disease in patients already suffering from COVID-19. Thus, it is a broad-spectrum drug. Apart from this drug, the program includes tyrosine kinase inhibitor interleukin 33 and Calquence drug. Under this program, approximately $\$ 8$ billion funding would be provided to several international agencies, research organizations, and industries by UK Research and Innovation (UKRI) and Department of Health and Social Care (DHSC).

BCG Vaccine for COVID-19 The BCG vaccine is known to improve frontline immunity. Every year, approximately 130 million children are vaccinated with BCG for tuberculosis. In Australia, Murdoch Children's Research Institute is conducting a clinical trial that shows that BCG vaccine reduces viral infections. It is estimated to be tried on more than 4000 frontline workers.

Killed Virus Vaccine Viruses are border organisms that are categorized neither among living nor among dead as these become activated only when they get into a host body. Therefore, a dead virus simply means the one in which infective capacity is removed off so that they cannot enter our body. This can be done either by chemical alteration or by extreme temperature treatment. Thus, using such dead virus vaccines may serve our purpose, but this is not always the case as dead viruses possess different altered protein than one produced by the live virus and so they do not prove very effective. Examples are flu, hepatitis A, etc.

Attenuated Virus Vaccine Such viruses are more effective than dead viruses as are live and draw out a strong immune response. But these vaccines provide only short-term immunity and their booster doses are required. Such weakened viruses are actual viruses with some mutations that make them more attracted to other animals than humans. Such viruses are created by culturing them in tissues of some other animal. Thus, a mutant form of the virus is chosen that would prefer other non-human animal hosts and would hardly infect humans. Vaccines made from such weakened viruses when injected into humans may provide immunity against viruses and at the same time avoid exaggerated infection. Thus, such vaccines usually show mild side effects post-treatment. Some of the examples are rotavirus, measles, mumps, rubella (MMR combined vaccine), smallpox, etc. Thus, both live and attenuated vaccines train our body to fight against infection as they are more natural. Some of the limitations of such vaccines include refrigeration to keep them alive; costly instrumentation to protect them from any new virulent mutation (or reversion) during transportation to distant places; reliability deficit in the effectiveness of the vaccine and safety after administration.

Conjugate Vaccines Sometimes viruses have some modulating or disguising outer envelope proteins that have the capacity to befool the host's immune system by concealing their antigens. Thus, such viruses go unnoticed by the host defense system and invade different organs. Live or weakened vaccines generally do not work in such cases, and thus, conjugate or subunit vaccines are made by attaching a characteristic antigen from some other familiar pathogen on to the virulent virus's coat. It works because the body's immune system learns to recognize this masked virus as a potential threat in the light of a known pathogen, e.g., Haemophilus influenzae type B (Hib).

Nucleic Acid Vaccines In this approach, DNA from the virus is genetically engineered (with specific spike protein genes) and introduced into the host body as a plasmid, thus eliciting an immune response against those antigens. This probably remains harmless but, in turn, teaches the body to identify harmful viruses and produce antibodies against them. But this has never been tested on humans to date and is not yet licensed ( $20 \%$ of current vaccine research focuses on this approach).

Recombinant Vaccines Specific spike protein-producing gene segments are inserted into vectors (adenovirus) for vaccine delivery. Adenoviruses are good vectors for vaccine development because they can infect a wide range of hosts; cause effective expression of transgene; can be cultured in laboratories at low cost; do not allow lysogeny of viral genes into host genes; and can trigger an immune response by infecting dendritic cells and target both systemic and mucosal immune response. Johnson and Johnson, a US-based company, is working on this project ( $26 \%$ of current vaccine research focuses on this approach). 
Virus-Like Particles (VLP) Specialized empty (without genetic material) lipid vesicles are prepared with spike proteins on the surface that mimic a true virus, and the body's immune system reacts in response to this. These could serve as excellent vaccine candidates (33\% of current vaccine research focuses on this approach).

\section{Conclusions and Future Challenges}

Worldwide, millions of people are infected, and thousands of deaths are occurring due to the pandemic situation of COVID19. Unfortunately, no therapeutics have yet been proven effective for the treatment of severe illness caused by SARS-CoV-2. The identification of effective strategies against SARS-CoV-2 is a major challenge. Currently, we are fighting a twenty-first century disease with twentieth century weapons. The clinical trials of repurposing the existing antiviral agents against this potentially fatal disease are going on across the world. Recently, several possibilities including targeting viral binding receptors (ACE2) and spike proteins, stimulating an immune response, monoclonal antibodies, peptides, small-molecule drugs, etc. are being explored against emerging SARS-CoV-2 infection. However, the whole world is facing a challenge in dealing with a new coronavirus infection that has just emerged in humans and we are not having the existing vaccine or a drug against this potentially fatal disease. We hope that through these accelerated and determined plans, very soon, an effective vaccine that targets SARS-CoV-2 will be developed to settle this global COVID-19 issue. In closing, we express our concern about fading away from these big programs and funds offered to sort this public health crisis (generally offered around such pandemic). We would be witnessing many new and far deadly viral pandemics in the ensuing time, and thus, we really need to be prepared to tackle this unseen danger. Thus, we need to continue this research with the same enthusiasm and zeal to discover reliable and affordable therapeutic strategies to curb such pandemics.

Acknowledgments The research presented in this article was supported by the National Institutes of Health (NIH) grants AG042178, AG047812, NS105473, AG060767, and AG069333 (to PHR). This research was also supported by the Alzheimer's Association New Investigator Research Grant 2016-NIRG-39787, the Center of Excellence for Translational Neuroscience and Therapeutics (PN-CTNT20115-AR), Alzheimer's Association through a SAGA grant, and NIH grant AG063162 (to AR). We acknowledge support from the Central University of Punjab, Bathinda, India. We thank all the doctors, nurses, health workers, and research scientists who are working day and night to fight against the COVID-19 pandemic. The figures were assembled using dynamic BioRender assets.

\section{Compliance with Ethical Standards}

Conflict of Interest The authors declare that they have no competing interests.

\section{References}

1. Guarner J (2020) Three emerging coronaviruses in two decades. Am J Clin Pathol 153(4):420-421. https://doi.org/10.1093/ajcp/ aqaa029

2. Drosten C, Günther S, Preiser W, Van Der Werf S, Brodt H-R, Becker S, Rabenau H, Panning M et al (2003) Identification of a novel coronavirus in patients with severe acute respiratory syndrome. N Engl J Med 348(20):1967-1976

3. Ksiazek TG, Erdman D, Goldsmith CS, Zaki SR, Peret T, Emery S, Tong S, Urbani C et al (2003) A novel coronavirus associated with severe acute respiratory syndrome. N Engl J Med 348(20):19531966

4. Zaki AM, van Boheemen S, Bestebroer TM, Osterhaus AD, Fouchier RA (2012) Isolation of a novel coronavirus from a man with pneumonia in Saudi Arabia. N Engl J Med 367(19):1814 1820. https://doi.org/10.1056/NEJMoa1211721

5. Huang C, Wang Y, Li X, Ren L, Zhao J, Hu Y, Zhang L, Fan G et al (2020) Clinical features of patients infected with 2019 novel coronavirus in Wuhan, China. Lancet 395(10223):497-506

6. World Health Organization (2004) WHO guidelines for the global surveillance of severe acute respiratory syndrome (SARS): updated recommendations, October 2004. World Health Organization, Geneva

7. Meo SA, Alhowikan AM, Al-Khlaiwi T, Meo IM, Halepoto DM, Iqbal M, Usmani AM, Hajjar W et al (2020) Novel coronavirus 2019-nCoV: prevalence, biological and clinical characteristics comparison with SARS-CoV and MERS-CoV. Eur Rev Med Pharmacol Sci 24(4):2012-2019. https://doi.org/10.26355/eurrev_ 20200220379

8. Cui J, Li F, Shi Z-L (2019) Origin and evolution of pathogenic coronaviruses. Nat Rev Microbiol 17(3):181-192

9. Guo YR, Cao QD, Hong ZS, Tan YY, Chen SD, Jin HJ, Tan KS, Wang DY et al (2020) The origin, transmission and clinical therapies on coronavirus disease 2019 (COVID-19) outbreak - an update on the status. Military Med Res 7(1):11. https://doi.org/10.1186/ s40779-020-00240-0

10. Chan JF-W, Yuan S, Kok K-H, To KK-W, Chu H, Yang J, Xing F, Liu J et al (2020) A familial cluster of pneumonia associated with the 2019 novel coronavirus indicating person-to-person transmission: a study of a family cluster. Lancet 395(10223):514-523

11. Li Q, Guan X, Wu P, Wang X, Zhou L, Tong Y, Ren R, Leung KS et al (2020) Early transmission dynamics in Wuhan, China, of novel coronavirus-infected pneumonia. N Engl J Med 382:1199-1207

12. World Health Organization (2020) Coronavirus disease (COVID19) outbreak. URL https://www.whoint/emergencies/diseases/ novel-coronavirus-2019 Accessed March

13. Meo S, Alhowikan A, Al-Khlaiwi T, Meo I, Halepoto D, Iqbal M, Usmani A, Hajjar W et al (2020) Novel coronavirus 2019-nCoV: prevalence, biological and clinical characteristics comparison with SARSCoV and MERS-CoV. Eur Rev Med Pharmacol Sci 24(4):2012-2019

14. World Health Organization (2020) Coronavirus disease 2019 (COVID-19): situation report, 194 (1st Aug 2020).

15. Huang C, Wang Y, Li X, Ren L, Zhao J, Hu Y, Zhang L, Fan G et al (2020) Clinical features of patients infected with 2019 novel coronavirus in Wuhan, China. Lancet 395(10223):497-506. https://doi. org/10.1016/S0140-6736(20)30183-5

16. Zavascki AP, Falci DR (2020) Clinical characteristics of Covid-19 in China. N Engl J Med 382:1859-1862. https://doi.org/10.1056/ NEJMc2005203

17. Guan WJ, Ni ZY, Hu Y, Liang WH, Ou CQ, He JX, Liu L, Shan H, Lei CL, Hui DSC, Du B, Li LJ, Zeng G, Yuen KY, Chen RC, Tang CL, Wang T, Chen PY, Xiang J, Li SY, Wang JL, Liang ZJ, Peng YX, Wei L, Liu Y, Hu YH, Peng P, Wang JM, Liu JY, Chen Z, Li G, Zheng ZJ, Qiu SQ, Luo J, Ye CJ, Zhu SY, Zhong NS, China Medical Treatment Expert Group for C (2020) Clinical 
characteristics of coronavirus disease 2019 in China. N Engl J Med https://doi.org/10.1056/NEJMoa2002032, 382, 1708, 1720

18. Passarelli PC, Lopez MA, Mastandrea Bonaviri GN, Garcia-Godoy F, D'Addona A (2020) Taste and smell as chemosensory dysfunctions in COVID-19 infection. Am J Dent 33(3):135-137

19. Dawson P, Rabold EM, Laws RL, Conners EE, Gharpure R, Yin S, Buono SA, Dasu T et al (2020) Loss of taste and smell as distinguishing symptoms of COVID-19. Clin Infect Dis. https:// doi.org/10.1093/cid/ciaa799

20. Gautier JF, Ravussin Y (2020) A new symptom of COVID-19: loss of taste and smell. Obesity. 28:848. https://doi.org/10.1002/oby.22809

21. Guan WJ, Liang WH, Zhao Y, Liang HR, Chen ZS, Li YM, Liu XQ, Chen RC, Tang CL, Wang T, Ou CQ, Li L, Chen PY, Sang L, Wang W, Li JF, Li CC, Ou LM, Cheng B, Xiong S, Ni ZY, Xiang J, Hu Y, Liu L, Shan H, Lei CL, Peng YX, Wei L, Liu Y, Hu YH, Peng P, Wang JM, Liu JY, Chen Z, Li G, Zheng ZJ, Qiu SQ, Luo J, Ye CJ, Zhu SY, Cheng LL, Ye F, Li SY, Zheng JP, Zhang NF, Zhong NS, He JX, China Medical Treatment Expert Group for C (2020) Comorbidity and its impact on 1590 patients with Covid-19 in China: a nationwide analysis. Eur Respir J https://doi.org/10. 1183/13993003.00547-2020, 55, 2000547

22. Gosain R, Abdou Y, Singh A, Rana N, Puzanov I, Ernstoff MS (2020) COVID-19 and cancer: a comprehensive review. Curr Oncol Rep 22(5):53. https://doi.org/10.1007/s11912-020-00934-7

23. Zhu L, She ZG, Cheng X, Qin JJ, Zhang XJ, Cai J, Lei F, Wang H et al (2020) Association of blood glucose control and outcomes in patients with COVID-19 and pre-existing type 2 diabetes. Cell Metab 31:1068 1077.e3. https://doi.org/10.1016/j.cmet.2020.04.021

24. Li X, Xu S, Yu M, Wang K, Tao Y, Zhou Y, Shi J, Zhou M et al (2020) Risk factors for severity and mortality in adult COVID-19 inpatients in Wuhan. J Allergy Clin Immunol 146:110-118. https:// doi.org/10.1016/j.jaci.2020.04.006

25. Chen J (2020) Pathogenicity and transmissibility of 2019-nCoV-A quick overview and comparison with other emerging viruses. Microbes Infect 22(2):69-71. https://doi.org/10.1016/j.micinf. 2020.01.004

26. Raj VS, Mou H, Smits SL, Dekkers DH, Muller MA, Dijkman R, Muth D, Demmers JA et al (2013) Dipeptidyl peptidase 4 is a functional receptor for the emerging human coronavirus-EMC. Nature 495(7440):251-254. https://doi.org/10.1038/nature12005

27. Li W, Moore MJ, Vasilieva N, Sui J, Wong SK, Berne MA, Somasundaran M, Sullivan JL et al (2003) Angiotensinconverting enzyme 2 is a functional receptor for the SARS coronavirus. Nature 426(6965):450-454. https://doi.org/10.1038/ nature 02145

28. Li G, Fan Y, Lai Y, Han T, Li Z, Zhou P, Pan P, Wang W et al (2020) Coronavirus infections and immune responses. J Med Virol 92(4):424-432. https://doi.org/10.1002/jmv.25685

29. Chan JF, Kok KH, Zhu Z, Chu H, To KK, Yuan S, Yuen KY (2020) Genomic characterization of the 2019 novel humanpathogenic coronavirus isolated from a patient with atypical pneumonia after visiting Wuhan. Emerg Microbes Infect 9(1):221-236. https://doi.org/10.1080/22221751.2020.1719902

30. Agostini ML, Andres EL, Sims AC, Graham RL, Sheahan TP, Lu X, Smith EC, Case JB et al (2018) Coronavirus susceptibility to the antiviral remdesivir (GS-5734) is mediated by the viral polymerase and the proofreading exoribonuclease. mBio 9(2):e00221-00218

31. Ren LL, Wang YM, Wu ZQ, Xiang ZC, Guo L, Xu T, Jiang YZ, Xiong $Y$ et al (2020) Identification of a novel coronavirus causing severe pneumonia in human: a descriptive study. Chin Med J 133: 1015-1024. https://doi.org/10.1097/CM9.0000000000000722

32. Lu R, Zhao X, Li J, Niu P, Yang B, Wu H, Wang W, Song H et al (2020) Genomic characterisation and epidemiology of 2019 novel coronavirus: implications for virus origins and receptor binding. Lancet 395(10224):565-574. https://doi.org/10.1016/s01406736(20)30251-8
33. Holshue ML, DeBolt C, Lindquist S, Lofy KH, Wiesman J, Bruce H, Spitters C, Ericson K, Wilkerson S, Tural A, Diaz G, Cohn A, Fox L, Patel A, Gerber SI, Kim L, Tong S, Lu X, Lindstrom S, Pallansch MA, Weldon WC, Biggs HM, Uyeki TM, Pillai SK, Washington State - nCo VCIT (2020) First case of 2019 novel coronavirus in the United States. N Engl J Med 382 (10):929 936. https://doi.org/10.1056/NEJMoa2001191

34. Aguiar ACC, Murce E, Cortopassi WA, Pimentel AS, Almeida M, Barros DCS, Guedes JS, Meneghetti MR et al (2018) Chloroquine analogs as antimalarial candidates with potent in vitro and in vivo activity. Int J Parasitol Drugs Drug Resist 8(3):459-464. https://doi. org/10.1016/j.ijpddr.2018.10.002

35. Wang M, Cao R, Zhang L, Yang X, Liu J, Xu M, Shi Z, Hu Z et al (2020) Remdesivir and chloroquine effectively inhibit the recently emerged novel coronavirus (2019- nCoV) in vitro. Cell Res 30(3): 269-271. https://doi.org/10.1038/s41422-020-0282-0

36. Yazdany J, Kim AHJ (2020) Use of hydroxychloroquine and chloroquine during the COVID-19 pandemic: what every clinician should know. Ann Intern Med 172:754-755. https://doi.org/10. 7326/M20-1334

37. Colson P, Rolain JM, Lagier JC, Brouqui P, Raoult D (2020) Chloroquine and hydroxychloroquine as available weapons to fight COVID-19. Int J Antimicrob Agents:105932. https://doi.org/10. 1016/j.ijantimicag.2020.105932

38. Guastalegname M, Vallone A (2020) Could chloroquine /hydroxychloroquine be harmful in coronavirus disease 2019 (COVID-19) treatment? Clin Infect Dis 71:888-889. https://doi. org $/ 10.1093 / \mathrm{cid} / \mathrm{ciaa321}$

39. Brown AJ, Won JJ, Graham RL, Dinnon KH III, Sims AC, Feng JY, Cihlar T, Denison MR et al (2019) Broad spectrum antiviral remdesivir inhibits human endemic and zoonotic deltacoronaviruses with a highly divergent RNA dependent RNA polymerase. Antivir Res 169:104541

40. de Wit E, Feldmann F, Cronin J, Jordan R, Okumura A, Thomas T, Scott D, Cihlar T et al (2020) Prophylactic and therapeutic remdesivir (GS-5734) treatment in the rhesus macaque model of MERS-CoV infection. Proc Natl Acad Sci 117(12):6771-6776

41. Sheahan TP, Sims AC, Leist SR, Schäfer A, Won J, Brown AJ, Montgomery SA, Hogg A et al (2020) Comparative therapeutic efficacy of remdesivir and combination lopinavir, ritonavir, and interferon beta against MERS-CoV. Nat Commun 11(1):1-14

42. Mulangu S, Dodd LE, Davey RT Jr, Tshiani Mbaya O, Proschan M, Mukadi D, Lusakibanza Manzo M, Nzolo D et al (2019) A randomized, controlled trial of Ebola virus disease therapeutics. N Engl J Med 381(24):2293-2303

43. Li G, De Clercq E (2020) Therapeutic options for the 2019 novel coronavirus (2019-nCoV). Nat Rev Drug Discov 19(3):149-150. https://doi.org/10.1038/d41573-020-00016-0

44. Rainsford K, Parke AL, Clifford-Rashotte M, Kean W (2015) Therapy and pharmacological properties of hydroxychloroquine and chloroquine in treatment of systemic lupus erythematosus, rheumatoid arthritis and related diseases. Inflammopharmacology 23(5):231-269

45. JCD S, Mariz HA, LFd RJ, PSSd O, Dantas AT, ALBP D, IdR P, Galdino SL et al (2013) Hydroxychloroquine decreases Th17related cytokines in systemic lupus erythematosus and rheumatoid arthritis patients. Clinics 68(6):766-771

46. Ben-Zvi I, Kivity S, Langevitz P, Shoenfeld Y (2012) Hydroxychloroquine: from malaria to autoimmunity. Clin Rev Allergy Immunol 42(2):145-153

47. Gladman DD, Urowitz MB, Senecal JL, Fortin PJ, Petty RE, Esdaile JM, Carrette S, Edworthy SM et al (1998) Aspects of use of antimalarials in systemic lupus erythematosus. J Rheumatol 25(5):983-985

48. Taylor JK, McMurray RV (2011) Medical therapy for systemic lupus erythematosus. J Miss State Med Assoc 52(2):39-43 
49. Liu J, Cao R, Xu M, Wang X, Zhang H, Hu H, Li Y, Hu Z et al (2020) Hydroxychloroquine, a less toxic derivative of chloroquine, is effective in inhibiting SARS-CoV-2 infection in vitro. Cell Discov 6:16. https://doi.org/10.1038/s41421-020-0156-0

50. Yao X, Ye F, Zhang M, Cui C, Huang B, Niu P, Liu X, Zhao L et al (2020) In vitro antiviral activity and projection of optimized dosing design of hydroxychloroquine for the treatment of severe acute respiratory syndrome coronavirus 2 (SARS-CoV-2). Clin Infect Dis 71:732-739. https://doi.org/10.1093/cid/ciaa237

51. Gautret P, Lagier JC, Parola P, Hoang VT, Meddeb L, Mailhe M, Doudier B, Courjon J, Giordanengo V, Vieira VE, Dupont HT, Honore S, Colson P, Chabriere E, La Scola B, Rolain JM, Brouqui P, Raoult D (2020) Hydroxychloroquine and azithromycin as a treatment of COVID-19: results of an open-label non-randomized clinical trial. Int J Antimicrob Agents:105949. https://doi.org/ 10.1016/j.ijantimicag.2020.105949

52. Vincent MJ, Bergeron E, Benjannet S, Erickson BR, Rollin PE, Ksiazek TG, Seidah NG, Nichol ST (2005) Chloroquine is a potent inhibitor of SARS coronavirus infection and spread. Virol J 2:69. https://doi.org/10.1186/1743-422X-2-69

53. Rolain JM, Colson P, Raoult D (2007) Recycling of chloroquine and its hydroxyl analogue to face bacterial, fungal and viral infections in the 21st century. Int J Antimicrob Agents 30(4):297-308. https://doi.org/10.1016/j.ijantimicag.2007.05.015

54. Devaux CA, Rolain JM, Colson P, Raoult D (2020) New insights on the antiviral effects of chloroquine against coronavirus: what to expect for COVID-19? Int J Antimicrob Agents:105938. https:// doi.org/10.1016/j.ijantimicag.2020.105938

55. Savarino A, Boelaert JR, Cassone A, Majori G, Cauda R (2003) Effects of chloroquine on viral infections: an old drug against today's diseases? Lancet Infect Dis 3(11):722-727. https://doi.org/10. 1016/s1473-3099(03)00806-5

56. Golden EB, Cho HY, Hofman FM, Louie SG, Schonthal AH, Chen TC (2015) Quinoline- based antimalarial drugs: a novel class of autophagy inhibitors. Neurosurg Focus 38(3):E12. https://doi.org/ 10.3171/2014.12.FOCUS14748

57. Hernandez AV, Roman YM, Pasupuleti V, Barboza JJ, White CM (2020) Hydroxychloroquine or chloroquine for treatment or prophylaxis of COVID-19: a living systematic review. Ann Intern Med. https://doi.org/10.7326/M20-2496

58. Boulware DR, Pullen MF, Bangdiwala AS, Pastick KA, Lofgren SM, Okafor EC, Skipper CP, Nascene AA et al (2020) A randomized trial of hydroxychloroquine as postexposure prophylaxis for Covid-19. N Engl J Med 383:517-525. https://doi.org/10.1056/ NEJMoa2016638

59. National Institutes of Health (2020) Coronavirus (COVID-19). https:// www.nih.gov/health- information/coronavirus. Accessed April 11, 2020

60. Hull MW, Montaner JS (2011) Ritonavir-boosted protease inhibitors in HIV therapy. Ann Med 43(5):375-388

61. Lim J, Jeon S, Shin H-Y, Kim MJ, Seong YM, Lee WJ, Choe K-W, Kang YM et al (2020) Case of the index patient who caused tertiary transmission of COVID-19 infection in Korea: the application of lopinavir/ritonavir for the treatment of COVID-19 infected pneumonia monitored by quantitative RT-PCR. J Korean Med Sci 35(6)

62. Cao B, Wang Y, Wen D, Liu W, Wang J, Fan G, Ruan L, Song B et al (2020) A trial of lopinavir-ritonavir in adults hospitalized with severe Covid-19. N Engl J Med 382:1787-1799. https://doi.org/10. 1056/NEJMoa2001282

63. Wang N, Shang J, Jiang S, Du L (2020) Subunit vaccines against emerging pathogenic human coronaviruses. Front Microbiol 11: 298. https://doi.org/10.3389/fmicb.2020.00298

64. Lan J, Ge J, Yu J, Shan S, Zhou H, Fan S, Zhang Q, Shi X, Wang Q, Zhang L (2020) Crystal structure of the 2019-nCoV spike receptorbinding domain bound with the ACE2 receptor. bioRxiv
65. Estefanía E, Flores R, Gómez-Lozano N, Aguilar H, López-Botet M, Vilches C (2007) Human KIR2DL5 is an inhibitory receptor expressed on the surface of NK and T lymphocyte subsets. J Immunol (Baltimore, $\mathrm{Md}:$ 1950) 178(7):4402-4410. https://doi. org/10.4049/jimmunol.178.7.4402

66. Cunningham L, Kimber I, Basketter DA, McFadden JP (2020) Why judiciously timed anti-IL 6 therapy may be of benefit in severe COVID-19 infection. Autoimmun Rev:102563 https://doi.org/10. 1016/j.autrev.2020.102563

67. Du Z, Sharma SK, Spellman S, Reed EF, Rajalingam R (2008) KIR2DL5 alleles mark certain combination of activating KIR genes. Genes Immun 9(5):470-480. https://doi.org/10.1038/gene.2008.39

68. Shaikh S, Rao A, Prasad P (2020) Indians do not have genetic protection against coronavirus, published research incorrectly interpreted.

69. Lopalco L (2010) CCR5: from natural resistance to a new anti-HIV strategy. Viruses 2(2):574-600. https://doi.org/10.3390/v2020574

70. Esteller M (2011) Non-coding RNAs in human disease. Nat Rev Genet 12(12):861-874. https://doi.org/10.1038/nrg3074

71. Kato M, Natarajan R (2014) Diabetic nephropathy-emerging epigenetic mechanisms. Nat Rev Nephrol 10(9):517-530. https://doi. org/10.1038/nrneph.2014.116

72. Kato M, Natarajan R (2015) MicroRNAs in diabetic nephropathy: functions, biomarkers, and therapeutic targets. Ann N Y Acad Sci 1353(1):72-88. https://doi.org/10.1111/nyas.12758

73. Zhang Y, Sun X, Icli B, Feinberg MW (2017) Emerging roles for microRNAs in diabetic microvascular disease: novel targets for therapy. Endocr Rev 38(2):145-168. https://doi.org/10.1210/er.2016-1122

74. Song R, Hu XQ, Zhang L (2019) Mitochondrial MiRNA in cardiovascular function and disease. Cells 8(12). https://doi.org/10.3390/ cells 8121475

75. Cao Q, Chen XM, Huang C, Pollock CA (2019) MicroRNA as novel biomarkers and therapeutic targets in diabetic kidney disease: an update. FASEB Bioadv 1(6):375-388. https://doi.org/10.1096/ fba.2018-00064

76. Jackson RJ, Standart N (2007) How do microRNAs regulate gene expression? Science's STKE: Signal Transduction Knowledge Environment 2007(367):re1. https://doi.org/10.1126/stke.3672007re1

77. Montgomery RL, Hullinger TG, Semus HM, Dickinson BA, Seto AG, Lynch JM, Stack C, Latimer PA et al (2011) Therapeutic inhibition of miR-208a improves cardiac function and survival during heart failure. Circulation 124(14):1537-1547. https://doi.org/ 10.1161/CIRCULATIONAHA.111.030932

78. Dickinson BA, Semus HM, Montgomery RL, Stack C, Latimer PA, Lewton SM, Lynch JM, Hullinger TG et al (2013) Plasma microRNAs serve as biomarkers of therapeutic efficacy and disease progression in hypertension-induced heart failure. Eur J Heart Fail 15(6):650-659. https://doi.org/10.1093/eurjhf/hft018

79. Pinti MV, Hathaway QA, Hollander JM (2017) Role of microRNA in metabolic shift during heart failure. Am J Phys Heart Circ Phys 312(1):H33-H45. https://doi.org/10.1152/ajpheart.00341.2016

80. Tanaka T, Narazaki M, Kishimoto T (2016) Immunotherapeutic implications of IL-6 blockade for cytokine storm. Immunotherapy 8(8):959-970. https://doi.org/10.2217/imt-2016-0020

81. immunomodulatory therapy in COVID-19: role of chloroquine and anti-IL-6 monoclonal antibodies. Int J Antimicrob Agents:105982 https://doi.org/10.1016/j.ijantimicag.2020.105982

82. Michot JM, Albiges L, Chaput N, Saada V, Pommeret F, Griscelli F, Balleyguier C, Besse B et al (2020) Tocilizumab, an anti-IL6 receptor antibody, to treat Covid-19-related respiratory failure: a case report. Ann Oncol 31:961-964. https://doi.org/10.1016/j. annonc.2020.03.300

Publisher's Note Springer Nature remains neutral with regard to jurisdictional claims in published maps and institutional affiliations. 